\title{
EVALUACIÓN DE LA EFICIENCIA DE REACTORES DE LECHO FIJO UTILIZANDO AGUAS MIELES RESIDUALES DE TRAPICHES ARTESANALES
}

\author{
EVALUATION OF THE EFFECTIVENESS OF FIXED BED REACTORS \\ USING WASTE WATER OF SUGAR CRAFT MILLS
}

\author{
Gloria Lucía, Cárdenas Calvachi \\ Ing. Química, Esp., Profesor Asistente Facultad de Ingeniería, Investigadora Grupo GIA, \\ Universidad Mariana. San Juan de Pasto, Colombia, glucardenas@umariana.edu.co \\ Robert Mauricio, Ramos Ramos \\ Ing. Químico, Esp., Msc, Profesor H.C. Universidad Mariana, Director Corporación Autónoma \\ Regional de Nariño. San Juan de Pasto, Colombia, mauramos2000@yahoo.com
}

Fecha de recepción: 18 de noviembre de 2008

Fecha de aprobación: 11 de junio de 2009

\section{RESUMEN}

El problema de tratamiento y disposición final de las aguas mieles residuales provenientes de los trapiches artesanales en el departamento de Nariño, en particular los asentados en el municipio de Sandoná, radica en su imposibilidad económica y tecnológica, dadas las características de subsistencia en que se basa su funcionamiento. El sistema de filtros anaerobios de flujo ascendente (FAFA) como unidad principal de tratamiento biológico en la degradación de azúcares, ofrece una buena alternativa por ser considerado eficiente, de relativos bajos costos de construcción, operación y mantenimiento, con el reto central de mantener las condiciones de hábitat adecuadas para el crecimiento de la biomasa al interior del reactor. Se evaluaron cuatro medios de contacto (concha marina, material sintético, material vitrificado y grava de río), a escala de laboratorio, para encontrar el lecho de soporte de FAFA más conveniente en condiciones controladas de temperatura, régimen de flujo y acondicionamiento previo del medio bacteriano. La concha marina y el material sintético, ofrecen características de resistencia, durabilidad y facilidad de consecución y alcanzan remociones de materia orgánica mayores del $80 \%$. Sin embargo, la concha marina alcanza las mayores remociones $(89,7 \%$ para DQO y $87,8 \%$ para DBO) gracias a su estructura física que ofrece un microambiente adecuado y por su composición química, fuente natural de alcalinidad y micronutrientes al sistema, lo que hace que se lo considere como el medio de contacto más adecuado para diseñar e implementar filtros anaerobios de lecho fijo en la industria artesanal panelera. 
Palabras clave: Trapiche, industria artesanal panelera, filtro anaerobio de lecho fijo de flujo ascendente (FAFA), concha marina, arranque y estabilización del reactor.

\begin{abstract}
The problem of treatment and final disposal of waste water coming from artisan sugar mills in the Department of Nariño, particularly those established in the Municipality of Sandoná. It lies in its economical and technological impossibility, according to its nature. The system of Up Flow Anaerobic Filter (UFAF) as the principal unit of biological treatment on the degradation of sugars, it offers a good alternative because they are considered to be efficient treatments associated with low costs of construction, operation and maintenance, with the challenge of maintaining a suitable habitat conditions for the growth of the biomass inside the reactor. The study evaluated four contact means marine shell, synthetic material, vitrified material and river gravel, through laboratory-scale testing, to find the FAFA's most suitable material under controlled conditions of temperature, flow regime and previous conditioning of the bacterial environment. The marine shell and synthetic material provide characteristics of toughness, durability and easiness of obtaining and allowing an efficient removal of organic material above $80 \%$. However, the marine shell reaches the highest removal (89.7\% for COD and $87.8 \%$ for BOD) thanks its physical structure that provides an adequate microenvironment and its chemical composition, natural source of alkalinity and micronutrients to the system, which is considered the most suitable contact mean to design and to implement the UFAF in the artisan sugar mills.
\end{abstract}

Key words: artisan sugar mills, Up Flow Anaerobic Filter (UFAF), marine shell media, starting and stabilization of the reactor.

\title{
INTRODUCCIÓN
}

En los trapiches del departamento de Nariño, el procesamiento de la caña de azúcar, una de las cinco más importantes cadenas productivas del Departamento de Nariño (Viloria de la Hoz, 2007), tiene lugar en el contexto de la economía campesina, en unidades de pequeña escala con alto uso de mano de obra y bajo nivel tecnológico. Frente a este panorama, uno de los principales retos en el manejo ambiental de los trapiches paneleros lo constituye el tratamiento y disposición final de las aguas mieles residuales, caracterizadas por su alto contenido de materia orgánica, representada especialmente por la presencia de azúcares (glucosa y sacarosa). El tratamiento convencional de este tipo de agua residual involucra costos que los dueños de trapiches en su mayoría no pueden subsidiar, dada la precaria situación económica de la población del área de estudio, reflejada en los altos índices de miseria y pobreza (Dane, 2005) y las características de subsistencia de la industria panelera en Nariño, que impiden reinversión y mejoramiento tecnológico a nivel de cultivo y procesamiento (España, 1994). El 68,7\% de los trapiches en Nariño se localiza en los municipios de Sandoná, Consacá, Ancuya 
y Linares, quienes aportan el 74,4\% de la producción departamental (URPA, 1983). Sandoná es el municipio que presenta la menor eficiencia económica de los cuatro mencionados (Luna, 1991), aporta cerca de 21.990 toneladas de caña de azúcar, representando el $24 \%$ del total departamental y posee en operación aproximadamente 25 trapiches (GPE, 2004).

El sector panelero de Nariño necesita certificar sus productos bajo el denominado "Sello Verde" que garantiza que la naturaleza del producto ha sido concebida sin generar procesos adversos o contaminantes de otros productos o recursos naturales, para poder garantizar su aceptación en los mercados nacionales e internacionales (GEN, 2006). Uno de los ejes de acción para lograrlo, se centra en adoptar un sistema de tratamiento de aguas residuales responsable y sostenible de acuerdo al contexto social y ambiental de la región, para evitar situaciones adversas que puedan desatar estados de insalubridad en la población y alteración del equilibrio de los ecosistemas ubicados en su área de influencia.

Dadas las características de eficiencia y costos relativamente bajos de construcción, operación y mantenimiento (Borja, 1992), y las características propias del agua residual (Gonzales et al., 1994), los sistemas anaerobios ofrecen una buena alternativa para depurar las aguas mieles residuales de este sector productivo. El filtro anaerobio de flujo ascendente (FAFA) es un reactor en cuyo interior se dispone de un medio de soporte o lecho, con régimen básico de flujo pistón. Varios estudios comprueban que las aguas residuales industriales de concentración media y alta ( $\geq 1500 \mathrm{mgDQO} / \mathrm{L})$ que tienen en común la presencia de cantidades elevadas de residuos fácilmente acidificables, responden de manera adecuada a tratamientos anaerobios con FAFA como el caso de lixiviados (Chí et al., 2004; Chavarro et al., 2006), aguas residuales domésticas (Held et al., 2002; Villegas et al., 2006; Paredes et al., 2003) y otros residuos provenientes de procesos agroindustriales como elaboración de lácteos (Ince et al., 2000), extracción de aceite de palma (Chaisri et al., 2007), de almidón de yuca (Torres et al., 2003) y destilación de alcohol (Rivera et al., 2002), estos últimos, muy similares al agua miel.

Este estudio busca determinar cuál es el mejor lecho para el montaje de los FAFA a escala de laboratorio, en condiciones controladas de temperatura, régimen de flujo y acondicionamiento previo del medio bacteriano, que permita una mayor adhesión y proliferación de los microorganismos capaces de degradar la materia orgánica presente en el agua miel. Los análisis de remoción correspondientes a cada reactor, se constituyen en el fundamento técnico que establece cuál de los medios de soporte evaluados es la alternativa más viable para la depuración anaerobia de las aguas residuales provenientes de los trapiches que permita facilitar, en diseños posteriores, la definición de criterios y parámetros adecuados para la proyección de un sistema de tratamiento eficiente, de bajo costo y que su operación y mantenimiento sean fáciles, adecuadas y permanentes. 


\section{MATERIALES Y MÉTODOS}

\subsection{MONTAJE DEL SISTEMA}

Siguiendo criterios y parámetros de diseño de FAFA recomendados en la literatura técnica (MDEC et al., 2000) y con fundamento en el conocimiento de procesos biológicos de la remoción de materia orgánica, se diseña y monta a escala de laboratorio un modelo acorde con el régimen de flujo previsto, el tipo y características del desecho a tratar y las condiciones físicas del medio bacteriano. Dicho modelo consta de cuatro reactores cilíndricos, cada uno con un volumen total de 6,6 litros y un volumen útil de 5,2 litros (Figura 1).
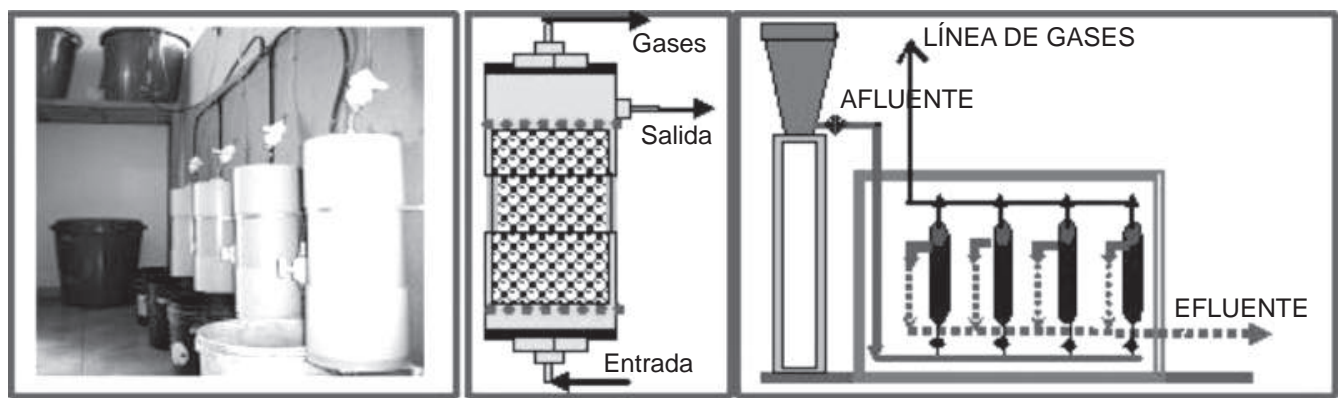

Figura 1. Vista general de los reactores FAFA y su montaje en un sistema de flujo por gravedad.

El sistema funciona por gravedad y en paralelo, con una cabeza hidráulica de 1,6 m desde la salida del tanque de carga hasta la entrada de cada reactor por su parte inferior. Con el objeto de regular la presión de salida a diferente nivel de vaciado del tanque de carga, se adaptó un dispositivo de cabeza constante (regulado por un flotador), con el cual se logró conseguir un caudal de 0,2 L/h y un tiempo de retención hidráulica (TRH) de 26 horas.

Para la selección de los medios de contacto de los reactores, se realizó un estudio previo donde se evaluaron algunos materiales, con base en criterios como: resistencia, durabilidad, economía, área específica y dificultad de obstrucción. Los cuatro materiales seleccionados fueron: concha marina en el reactor 1 , material sintético en el reactor 2 , material vitrificado en el reactor 3 y grava de río en el reactor 4 , con un área específica o área superficial total por unidad de volumen del material sólido (Bear, 1988) de 1.210, 2.027, 446 y $189 \mathrm{~m}^{2} / \mathrm{m}^{3}$ respectivamente (Ver Figura 2). La disposición de los medios de contacto se realizó de manera aleatoria.

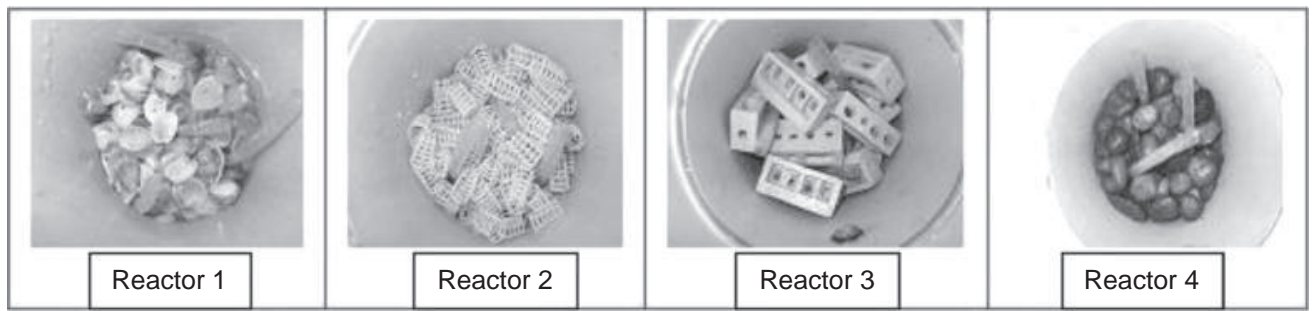

Figura 2. Disposición de los medios de contacto en el interior de los reactores. 


\subsection{PARÁMETROS DE CONTROL}

Los parámetros de control se analizaron en laboratorio. El pH se midió con un electrodo combinado; la alcalinidad y la demanda bioquímica de oxígeno al quinto día - $\mathrm{DBO}_{5}$, se determinaron mediante titulación; la demanda química de oxígeno total - DQO por reflujo cerrado titulométrico y los ácidos grasos volátiles - AGV por destilación. Todos los procedimientos utilizados están normalizados según los métodos estándar (APHA et al., 1989).

\subsection{METODOLOGÍA}

\subsubsection{Arranque de los reactores}

En el arranque de los reactores se tiene en cuenta la influencia de la concentración y composición del agua residual, el volumen, actividad y adaptación del inóculo, las condiciones ambientales, los parámetros de operación y por último la configuración del reactor. Todos ellos se encuentran estrechamente relacionados (Noyola, 1994).

En cuanto al agua residual se utiliza el agua miel generada en los trapiches del municipio de Sandoná que se caracteriza por su alto contenido de materia orgánica (especialmente azúcares como glucosa y sacarosa), de concentraciones y caudales variables, dependiendo del sitio y tipo de lavado requerido en la producción diaria. Según los registros existentes (Corponariño, 2004), sobre diferentes monitoreos efectuados en varios trapiches de este municipio, se estima que estos vierten aguas residuales con concentraciones promedio de $5000 \mathrm{mgDQO} / \mathrm{l}$, con caudales intermitentes del orden de los 0,5 litros por segundo (L/s) en un período aproximado de 2 horas durante el día $\left(3,6 \mathrm{~m}^{3} / \mathrm{d}\right)$, periodo que coincide con la jornada de saneamiento al finalizar el día de trabajo. Lo anterior implica que la carga contaminante diaria vertida es de 18 kilogramos de DQO. Para la investigación, se toma la muestra de un trapiche representativo, después de la sedimentación primaria y en el laboratorio, se acondiciona el agua miel realizando una dilución de la misma para alcanzar la concentración de sustrato necesaria. Así, la concentración requerida en la inoculación fue de 500 mgDQO/L.

Como inóculo activo, se utilizó un extracto compuesto por material biológico existente en el contenido rumenal de la vaca, mezclado en parte con caldos bacterianos provenientes de los otros estómagos y estiércol de los intestinos del rumiante recién obtenidos de la sala de sacrificio. El rumen en la vaca provee un ambiente apropiado, con alto contenido de bacterias metanogénicas tales como los bacilos Methanobrevibacter ruminantium y Methanomicro-bium mobile (Hobson, 1988) y con un suministro generoso de alimentos para el crecimiento y reproducción de los microorganismos (bacterias, protozoos y hongos) fundamentales en el proceso gradual de adaptación del medio microbiano a la metabolización del nuevo sustrato (agua miel). La preparación del extracto, comienza con el transporte del contenido rumenal fresco, evitando al máximo el contacto con el oxígeno del aire y la luz solar. Posteriormente se realiza 
una dilución con agua de río utilizando una relación rumen/agua de 4:6. Debidamente mezclada se pasa la dilución a través de un tamiz fino, recolectando únicamente el extracto diluido libre de la fibra estomacal.

El filtrado del contenido rumenal que se constituyó en la fuente del inóculo fue llenado en los reactores hasta un $80 \%$ de su volumen. El volumen se completó con agua miel a una concentración de 500 mgDQO/L. Esta solución se dejó por tres días en total. Finalizando cada día del periodo de inoculación, se retiró un litro del contenido del reactor, remplazándolo por un litro de agua miel diluida.

\subsubsection{Operación de los reactores}

Realizada la inoculación y finalizados los tres días en los que se intercambió diariamente un litro de agua de reactor por agua miel diluida (a $500 \mathrm{mgDQO} / \mathrm{L}$ ), se puso en marcha la alimentación del sistema de reactores desde el tanque elevado, regulando mediante las válvulas de entrada, un caudal constante de alimentación para cada reactor de 0,2 $\mathrm{L} / \mathrm{h}$ de agua miel en concentraciones bajas que inicialmente oscilan entre 500 y 1.000 $\mathrm{mgDQO} / \mathrm{L}$, concentración que es incrementada a medida que el medio bacteriano se adhiere al medio de soporte y se acostumbra a degradar esta materia orgánica. Esta adaptación se mide con la disminución de los AGV de 5 miliequivalentes por litro (meq/ L) a niveles cercanos a 3, entendiéndose esta condición como el reestablecimiento del equilibrio metabólico entre la acidogénesis, acetogénesis y metanogénesis, y por ende, la adaptabilidad de la biomasa a sobrecargas controladas de sustrato (Zegers, 1987).

Con este procedimiento, la concentración de entrada al sistema se va incrementando en la fase de operación normal hasta rangos de concentración de 4.000 a 5.500 mgDQO/L. Finalizada esta fase de operación normal se continua alimentando los reactores con mayores cargas volumétricas de aguas mieles, lo que permite evaluar la capacidad del medio microbiológico para metabolizar picos de cargas orgánicas presentados en las etapas iniciales de lavado de trapiches o en períodos de contingencias y verificar la concentración y carga límite de DQO bajo la cual son aún eficientes los microorganismos anaerobios en las condiciones limitantes de volumen de los reactores y de área de contacto disponible en los lechos de soporte. Inicialmente la alimentación se hizo con una concentración entre 6000 y 7000 mgDQO/L, seguida de una concentración entre 9000 y 10000 mgDQO/L y finalmente entre 11000 y 12000 mg/L.

En lo que respecta al hábitat en el cual debe desarrollarse el medio biológico, el pH en el interior de los reactores fue controlado entre 6,2 y 7,6 con la adición de una solución de $\mathrm{NaOH}$ y $\mathrm{CaCO}_{3}$ al $3 \%$ desde el tanque de carga, manteniendo la alcalinidad en valores comprendidos entre 800 y $1.100 \mathrm{mg} \mathrm{CaCO}_{3} / \mathrm{L}$. En cuanto a la temperatura adecuada para favorecer el crecimiento biológico, el proyecto a escala de laboratorio requirió la utilización de un calentador de ventilación continua que mantenía el ambiente en un rango 
entre 28 y $30^{\circ} \mathrm{C}$, lo que permitía mantener una temperatura en el interior de los reactores superior a los $30^{\circ} \mathrm{C}$. Las necesidades de nutrientes se garantizaron con una solución de urea y concentrado nitrógeno-fósforo-potasio NPK al 3\%, manteniendo una relación DBO:N:P de 100:5:1 recomendada para aguas residuales acidificadas (Speece, 1996; Crites et al., 2000). Esta relación fue mantenida en todo el proceso desde el arranque hasta la operación del sistema.

\section{RESULTADOS Y ANÁLISIS}

La adaptación del medio bacteriano al medio de soporte y al sustrato medida con la disminución de los AGV a niveles cercanos a $3 \mathrm{meq} / \mathrm{L}$ transcurre generalmente en un período de 2 a 3 días, después de los cuales se aumenta la carga volumétrica incrementando la concentración de DQO de agua miel a la entrada a caudal constante. Así para la fase de operación normal, se utilizaron cargas volumétricas de entrada de 3,7 - 5,1 $\mathrm{KgDQO} / \mathrm{m}^{3}$.d con concentraciones de 4.000 a $5.500 \mathrm{mgDQO} / \mathrm{L}$. Los resultados obtenidos, medidos como AGV y DQO del efluente se presentan en la Figura 3.
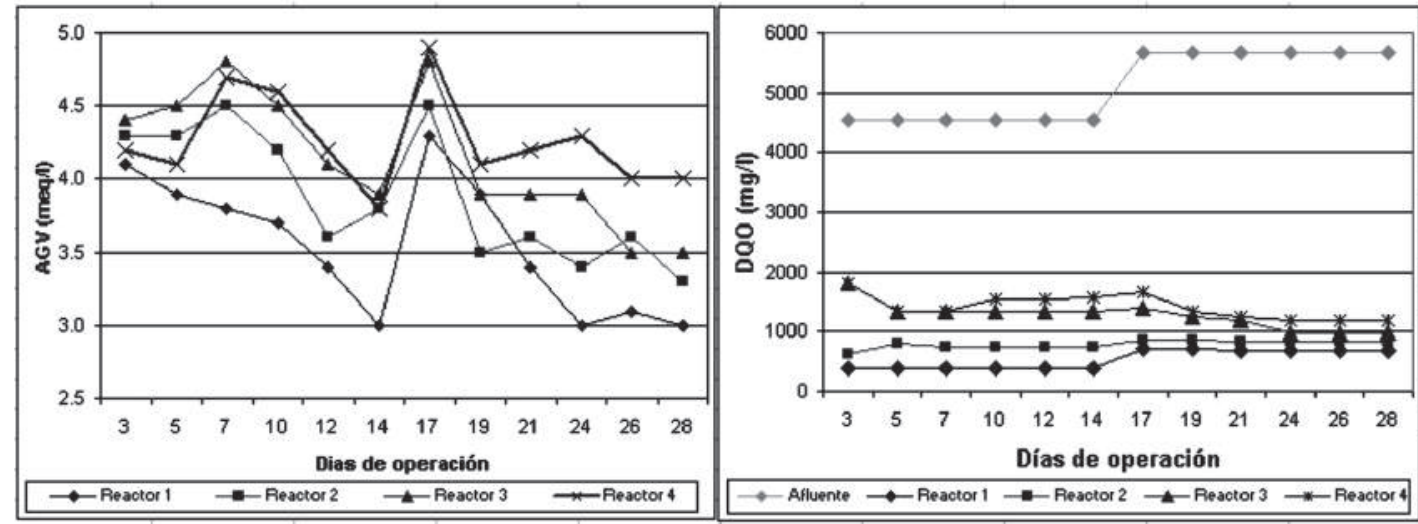

Figura 3. Evolución de los AGV y la DQO del efluente en el sistema de reactores.

El mejor comportamiento en cuanto a reducción de materia orgánica, teniendo en cuenta los menores valores de DQO a la salida, se presenta en los reactores 1 y 2 , con lecho de concha marina y material sintético respectivamente. La Tabla 1 y la Figura 4 muestran la evolución de las fases en términos de remoción de materia orgánica.

Los reactores 1 y 2 superan el $80 \%$ de remoción en carga exigida por la norma colombiana (MAC,1984), que a caudal constante $(0,2 \mathrm{~L} / \mathrm{h})$ puede ser medida igualmente en términos de concentración, situación que ubica a la concha marina como el material más indicado para desarrollar un medio biológico anaerobio capaz de adaptarse y degradar la materia orgánica presente en las aguas mieles residuales de los trapiches, seguido por el material sintético, el medio refractario y finalmente la grava de río. 
Tabla 1. Eficiencia de remoción de materia orgánica (DQO y DBO) por cada fase

\begin{tabular}{|l|c|c|c|c|c|c|c|c|c|c|c|c|}
\hline \multirow{2}{*}{ Fase } & \multicolumn{10}{c|}{ Remoción de DQO } \\
\cline { 2 - 15 } & $\begin{array}{c}\text { Prom. } \\
(\%)\end{array}$ & $\begin{array}{c}\text { Desviac. } \\
\text { estandar }\end{array}$ & $\mathrm{n}$ & $\begin{array}{c}\text { Prom. } \\
(\%)\end{array}$ & $\begin{array}{c}\text { Desviac. } \\
\text { estandar }\end{array}$ & $\mathrm{n}$ & $\begin{array}{c}\text { Prom. } \\
(\%)\end{array}$ & $\begin{array}{c}\text { Desviac. } \\
\text { estandar }\end{array}$ & $\mathrm{n}$ & $\begin{array}{c}\text { Prom. } \\
(\%)\end{array}$ & $\begin{array}{c}\text { Desviac. } \\
\text { estandar }\end{array}$ & $\mathrm{n}$ \\
\hline Arranque & 48,6 & 16,9 & 6 & 44,2 & 13,7 & 6 & 25,1 & 8,6 & 6 & 34,5 & 16,5 & 6 \\
\hline $\begin{array}{l}\text { Estabiliza- } \\
\text { ción }\end{array}$ & 80,0 & 17,4 & 15 & 78,2 & 16,4 & 15 & 67,7 & 20,3 & 15 & 67,3 & 20,4 & 15 \\
\hline $\begin{array}{l}\text { Operación } \\
\text { normal }\end{array}$ & 89,7 & 1,8 & 12 & 84,4 & 1,2 & 12 & 74,4 & 6,9 & 12 & 71,6 & 6,6 & 12 \\
\hline
\end{tabular}

\begin{tabular}{|c|c|c|c|c|c|c|c|c|c|c|c|c|}
\hline & \multicolumn{9}{c|}{ Remoción de DBO } \\
\cline { 2 - 11 } & \multicolumn{3}{|c|}{ Reactor 1 } & \multicolumn{3}{c|}{ Reactor 2 } & \multicolumn{2}{c|}{ Reactor 3 } & \multicolumn{3}{c|}{ Reactor 4 } \\
\cline { 2 - 11 } & $\begin{array}{c}\text { Prom. } \\
(\%)\end{array}$ & $\begin{array}{c}\text { Desviac. } \\
\text { estandar }\end{array}$ & $\mathrm{n}$ & $\begin{array}{c}\text { Prom. } \\
(\%)\end{array}$ & $\begin{array}{c}\text { Desviac. } \\
\text { estandar }\end{array}$ & $\mathrm{n}$ & $\begin{array}{c}\text { Prom. } \\
(\%)\end{array}$ & $\begin{array}{c}\text { Desviac. } \\
\text { estandar }\end{array}$ & $\mathrm{n}$ & $\begin{array}{c}\text { Prom. } \\
(\%)\end{array}$ & $\begin{array}{c}\text { Desviac. } \\
\text { estandar }\end{array}$ & $\mathrm{n}$ \\
\hline $\begin{array}{c}\text { Operación } \\
\text { normal }\end{array}$ & 87,8 & 1,6 & 6 & 84,7 & 1,3 & 6 & 78,7 & 3,6 & 6 & 75,4 & 3,2 & 6 \\
\hline
\end{tabular}
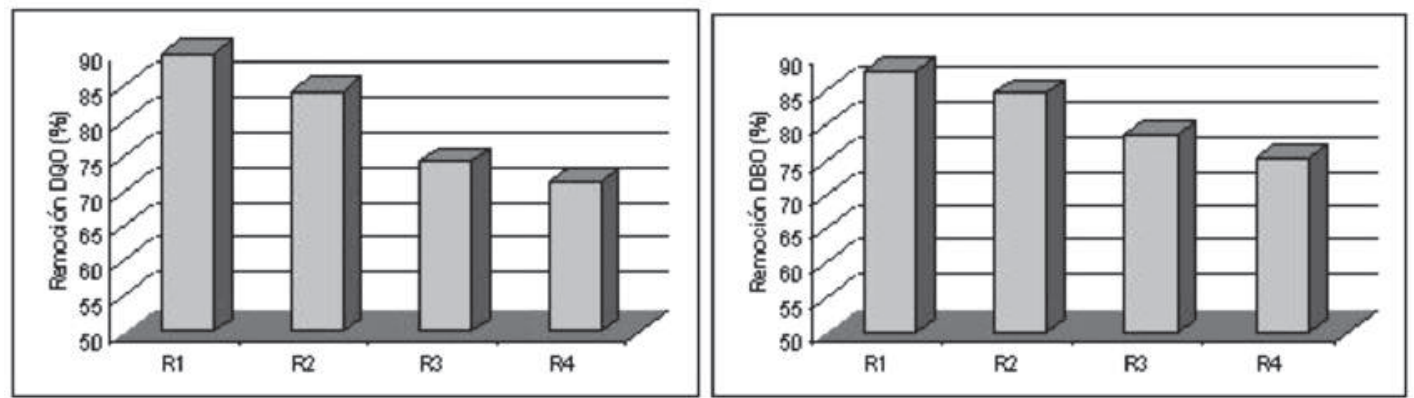

Figura 4. Remoción de $\mathrm{DQO}$ y $\mathrm{DBO}_{5}$ durante la operación normal del sistema.

La fase de operación con mayores cargas volumétricas de aguas mieles (6, 8,8 y 10,6 gDQO/L.d), obtenidas con concentraciones de DQO entre 6000 y 7000 mg/L, entre 9000 y $10000 \mathrm{mg} / \mathrm{L}$ y finalmente entre 11000 y $12000 \mathrm{mg} / \mathrm{L}$, fue medida en periodos de 14 días para cada rango. En este nuevo régimen de alimentación de los reactores, el nivel de AGV se incrementó oscilando entre 4,5 y $5 \mathrm{meq} / \mathrm{L}$, con respecto a la operación normal que registraba valores cercanos a 3; el nivel más alto de los AGV va acompañado con una moderada disminución en los porcentajes de remoción de la materia orgánica, tal como se observa en la Tabla 2 y en la Figura 5. 
Tabla 2. Eficiencia de remoción de materia orgánica en la fase de operación con altas concentraciones

\begin{tabular}{|c|c|c|c|c|c|c|c|c|c|c|c|c|}
\hline \multirow{3}{*}{$\begin{array}{c}\text { Alimentación } \\
\text { de Alta } \\
\text { Carga }\end{array}$} & \multicolumn{12}{|c|}{ Remoción de DQO } \\
\hline & \multicolumn{3}{|c|}{ Reactor 1} & \multicolumn{3}{|c|}{ Reactor 2} & \multicolumn{3}{|c|}{ Reactor 3} & \multicolumn{3}{|c|}{ Reactor 4} \\
\hline & $\begin{array}{c}\text { Prom. } \\
(\%)\end{array}$ & $\begin{array}{l}\text { Desviac. } \\
\text { estandar }\end{array}$ & $\mathrm{n}$ & $\begin{array}{c}\text { Prom. } \\
(\%)\end{array}$ & $\begin{array}{l}\text { Desviac. } \\
\text { estandar }\end{array}$ & $n$ & $\begin{array}{c}\text { Prom. } \\
(\%)\end{array}$ & $\begin{array}{l}\text { Desviac. } \\
\text { estandar }\end{array}$ & $n$ & $\begin{array}{c}\text { Prom. } \\
(\%)\end{array}$ & $\begin{array}{l}\text { Desviac. } \\
\text { estandar }\end{array}$ & $n$ \\
\hline $\mathrm{DQO}>6 \mathrm{~g} / \mathrm{L}$ & 86,1 & 0,2 & 6 & 82,3 & 0,1 & 6 & 77,6 & 0,0 & 6 & 72,0 & 0,1 & 6 \\
\hline $\mathrm{DQO}>9 \mathrm{~g} / \mathrm{L}$ & 72,7 & 0,3 & 6 & 71,5 & 0,4 & 6 & 68,0 & 0,3 & 6 & 66,3 & 0,2 & 6 \\
\hline $\mathrm{DQO}>11 \mathrm{~g} / \mathrm{L}$ & 64,4 & 0,4 & 6 & 62,8 & 0,1 & 6 & 56,5 & 0,1 & 6 & 53,8 & 0,1 & 6 \\
\hline
\end{tabular}

\begin{tabular}{|c|c|c|c|c|c|c|c|c|c|c|c|c|}
\hline \multirow{3}{*}{$\begin{array}{c}\text { Alimentación } \\
\text { de Alta } \\
\text { Carga }\end{array}$} & \multicolumn{12}{|c|}{ Remoción de DBO } \\
\hline & \multicolumn{3}{|c|}{ Reactor 1} & \multicolumn{3}{|c|}{ Reactor 2} & \multicolumn{3}{|c|}{ Reactor 3} & \multicolumn{3}{|c|}{ Reactor 4} \\
\hline & $\begin{array}{c}\text { Prom. } \\
(\%)\end{array}$ & $\begin{array}{l}\text { Desviac. } \\
\text { estandar }\end{array}$ & $n$ & $\begin{array}{c}\text { Prom. } \\
(\%)\end{array}$ & $\begin{array}{l}\text { Desviac. } \\
\text { estandar }\end{array}$ & $n$ & $\begin{array}{c}\text { Prom. } \\
(\%)\end{array}$ & $\begin{array}{l}\text { Desviac. } \\
\text { estandar }\end{array}$ & $n$ & $\begin{array}{c}\text { Prom. } \\
(\%)\end{array}$ & $\begin{array}{l}\text { Desviac. } \\
\text { estandar }\end{array}$ & $n$ \\
\hline $\mathrm{DQO}>6 \mathrm{~g} / \mathrm{L}$ & 75,6 & 1,8 & 3 & 70,1 & 1,3 & 3 & 67,5 & 0,8 & 3 & 61,9 & 1,3 & 3 \\
\hline $\mathrm{DQO}>9 \mathrm{~g} / \mathrm{L}$ & 70,8 & 4,3 & 4 & 66,0 & 1,7 & 4 & 63,7 & 0,9 & 4 & 62,0 & 1,3 & 4 \\
\hline $\mathrm{DQO}>11 \mathrm{~g} / \mathrm{L}$ & 47,5 & 0,2 & 6 & 46,2 & 0,3 & 6 & 45,7 & 0,2 & 6 & 45,4 & 0,2 & 6 \\
\hline
\end{tabular}

El pH para todas las concentraciones de alimentación de los reactores se mantuvo en niveles superiores a 6,2 unidades, gracias a los incrementos controlados de la alcalinidad desde el tanque de carga, estabilizando el potencial de acidificación que tienen los azúcares en la fermentación del residuo y manteniendo una relación AGV/alcalinidad menor que 0,4 valor por debajo del límite mencionado como condición de falla (Borja, 1992). El control debe ser más exhaustivo puesto que el proceso de acidificación convierte a los AGV en la forma no ionizada como tóxicos para la metanogénesis, pues a un $\mathrm{pH}$ de 5 , éstos pueden estar disociados en un $50 \%$ aproximadamente e inhibir drásticamente el metabolismo metanogénico (Zegers, 1987).

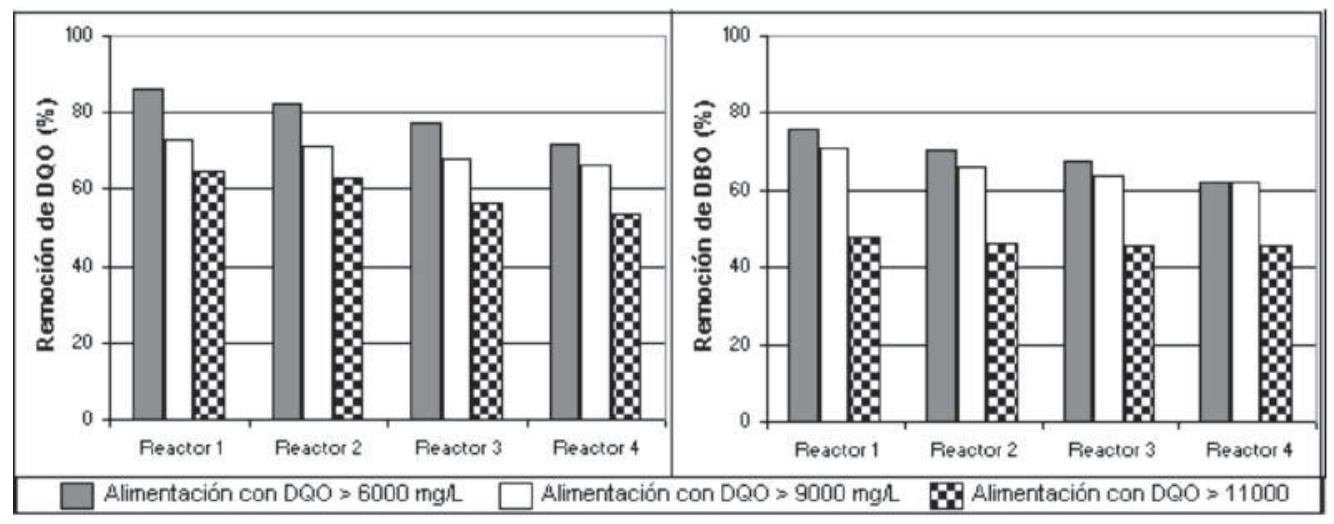

Figura 5. Remoción de $\mathrm{DQO}$ y $\mathrm{DBO}_{5}$ bajo alimentación con altas concentraciones. 
Nótese en la Figura 5, los progresivos descensos en la remoción de materia orgánica, indicando que para las condiciones de diseño de los reactores y operación del ensayo a escala de laboratorio, la sobrealimentación del sistema con este tipo de residuo líquido puede tener un tope máximo tolerable que puede ser degradado con eficiencia. Bajo estas condiciones, la tendencia indica que la utilización de un afluente con concentraciones mayores a $7 \mathrm{gDQO} / \mathrm{L}\left(>6,5 \mathrm{KgDQO} / \mathrm{m}^{3} . \mathrm{d}\right)$ puede reducir la eficiencia de remoción de materia orgánica por debajo del $80 \%$ y en concentraciones superiores con valores de remoción muy por debajo de las normas de vertimiento contempladas en la legislación vigente (MAC, 1984). Igual interpretación obedece a la variación de remoción de la $\mathrm{DBO}_{5}$. Sin embargo, las eficiencias de remoción de $\mathrm{DQO}$ y $\mathrm{DBO}_{5}$ en los reactores 1 y 2 siguen mostrando mejores comportamientos.

Finalmente, la concha marina seguida del material sintético son los medios de contacto que permiten las mejores condiciones de adaptación, adhesión y proliferación del medio biológico inoculado para el tratamiento anaerobio de las aguas mieles residuales de los trapiches artesanales, en diferentes regímenes de alimentación del sistema. Esta situación se ve reflejada en la fase de operación normal, con cargas volumétricas de 3,7 - 5,1 $\mathrm{KgDQO} / \mathrm{m}^{3}$.d y un TRH de 26 horas, donde se obtiene eficiencias de remoción de DQO y DBO de $89,7 \%$ y $87,8 \%$ respectivamente para el lecho de concha marina y de $84,4 \%$ y 84,7 para el material sintético.

Estos resultados de remoción de materia orgánica se asemejan a otros estudios de FAFA con diferentes medios de soporte en el tratamiento de aguas residuales con características similares al agua miel y bajo condiciones similares a las reportadas en la presente investigación. En el caso de aguas residuales provenientes de la destilación de alcohol, se alcanzan eficiencias de remoción superiores al 65\%, en operaciones a temperaturas de $20 \stackrel{\circ}{\circ}-25^{\circ} \mathrm{C}$, TRH de 2 días y cargas orgánicas inferiores a 7,32 $\mathrm{KgDQO} / \mathrm{m}^{3} \mathrm{~d}(\mathrm{Ri}$ vera et al., 2002). Un estudio en efluentes de extracción de almidón de yuca, donde se evaluaron diferentes medios, comprueba que la cáscara de coco es el medio que obtiene las mejores condiciones operacionales y eficiencias de remoción de DQO y SST (70 y $90 \%$ respectivamente), que a la vez resulta ser una alternativa muy competitiva por bajos precios y facilidad de adquisición (Torres et al., 2003). En el tratamiento de agua residual láctea, operando con una carga orgánica de $21 \mathrm{KgDQO} / \mathrm{m}^{3} \mathrm{~d}$ y un $\mathrm{TRH}$ de 0,5 días se obtuvo una eficiencia de remoción de DQO del $80 \%$ en un FAFA que tenía perlas de vidrio como lecho (Ince et al., 2000). En el tratamiento de efluentes de industrias de aceite de palma, se alcanzaron eficiencias de remoción de DQO mayores al 60\% en un FAFA que tuvo, en la etapa de operación experimental, un incremento gradual de 1,1 a $10 \mathrm{KgDQO} /$ $\mathrm{m}^{3}$.d y una disminución en el TRH 13,5 a 1.50 días (Chaisri et al., 2007).

Una de las principales razones explicativas de los buenos resultados para los medios de concha marina y material sintético, está en la magnitud de la superficie específica en ambos medios, además de la heterogeneidad de la superficie y composición química de 
la concha marina. Con relación a los otros medios estudiados, material vitrificado y grava de río, la concha tiene un área específica 2,7 y 6,4 veces mayor y el material sintético 4,5 y 10,7 veces mayor respectivamente. Adicionalmente, la concha marina presenta una gran heterogeneidad de la superficie lo que hace que, conjuntamente con el área específica, ofrezca un mayor número de microambientes que influyen sobre la densidad y composición taxonómica de la comunidad microbiológica inoculada (Prieur, 1993). La composición química de la concha, tiene una matriz orgánica de naturaleza fundamentalmente proteínica (conquiolina) que contiene una gran cantidad de aminoácidos y algunos aminoazúcares y un depósito inorgánico de cristales de sales como carbonato de calcio y carbonatos, fosfatos y silicatos de magnesio, siendo la primera la más abundante (Barnes, 1966). Esta estructura química puede ser una fuente de alcalinidad y de macro y micronutrientes para el medio biológico, que hace que su adaptación, adhesión y proliferación, conviertan a la concha marina como el medio más eficiente.

\section{CONCLUSIONES}

El FAFA con concha marina como medio de soporte es la mejor opción como unidad principal para el tratamiento biológico de las aguas mieles residuales provenientes de trapiches artesanales, seguido del material sintético, por presentar las mayores eficiencias de remoción de materia orgánica en términos de DQO y DBO en todas las fases (arranque, estabilización y operación normal) en comparación con los otros materiales evaluados. En el caso de la operación normal con cargas de alimentación de agua miel de $3,7-5,1 \mathrm{KgDQO} / \mathrm{m}^{3}$.d y un TRH de 26 horas, se obtuvo $89,7 \%$ para DQO y de $87,8 \%$ para $\mathrm{DBO}_{5}$ en el reactor con lecho de concha marina y $84,4 \%$ para DQO y $84,7 \%$ para $\mathrm{DBO}_{5}$ en el reactor con lecho de material sintético. En la etapa de alimentación con altas cargas volumétricas, la eficiencia se reduce por debajo del $80 \%$; el tope máximo tolerable del sistema se considera una carga volumétrica de alimentación de $6,5 \mathrm{KgDQO} / \mathrm{m}^{3} \mathrm{~d}$.

Los mejores resultados obtenidos por los reactores con concha marina y material sintético como medios de soporte, se deben principalmente a la diferencia en la magnitud de la superficie específica en ambos medios en comparación con los otros, y además, en el caso de la concha marina, a su estructura física y composición química.

La superficie heterogénea de la concha marina hace que se establezca un mayor número de microambientes que influyen sobre la densidad y composición taxonómica de la comunidad microbiológica inoculada. La naturaleza química de origen proteínico y de origen inorgánico (sales como carbonatos, fosfatos y silicatos) se constituye en una fuente de nutrientes de alcalinidad que puede lograr contrarrestar en alguna medida la acidificación rápida y la copiosa generación de AGV que puede desestabilizar el sistema.

La comparación de los resultados obtenidos en esta investigación con estudios similares (Rivera, Torres y otros) que evalúan diferentes medios de soporte y utilizan aguas 
residuales con características parecidas al agua miel y bajo condiciones similares a las reportadas en la presente investigación, permiten concluir que los FAFA pueden ser utilizados en el tratamiento primario o secundario para disminuir de manera eficiente la carga contaminante de residuos con concentraciones medias y altas de materia orgánica fácilmente acidificable.

\section{REFERENCIAS BIBLIOGRÁFICAS}

[1] APHA, AWWA \& WPCF. (1989). Métodos normalizados para el análisis de aguas potables y residuales (17ª Edición). Madrid. Editorial Diaz de Santos S.A.

[2] BARNES, Robert D. (1995) Zoología de los invertebrados. 5.ed. México. Interamericana; McGraw-Hill. 957 p.

[3] BEAR, Jacob (1988). Dynamics of fluids in porous media. New York. Dover Publications, Inc. $764 \mathrm{p}$.

[4] BORJA PADILLA, Rafael (1992). Control de reactores anaerobios: parámetros y procedimientos. Ciudad de La Habana, Cuba. Centro Nacional de Investigaciones Científicas; Instituto Cubano de Investigaciones de los Derivados de la Caña de Azúcar; Universidad Nacional Autónoma de México. Segundo Taller Regional Tratamiento Anaerobio de Aguas Residuales en América Latina. p.1-25.

[5] CHAISRI, Ronnachai; BOONSAWANG, Piyarat; PRASERTSAN, Poonsuk y CHAIPRAPAT, Sumate. (2007). Effect of organic loading rate on methane and volatile fatty acids productions from anaerobic treatment of palm oil mill effluent in UASB and UFAF reactors; En: Songklanakarin Journal of Science and Technology ISSN: 01253395, Vol. 29, pp. 311323

[6] CHAVARRO, Mauricio; GARCÉS, Juan; GUERRERO, Jhoniers y SALAS, Diana. (2006) Evaluación de la tratabilidad de los lixiviados en el Relleno Sanitario de Pereira mediante filtros anaerobios de flujo ascendente a escala piloto; En: Scientia et Technica ISSN $0122-$ 1701, Año XII, No 30.

[7] CHÍ, Trân Minh; NHUÊ, Trân Hieu y TRIÊT, Lâm Minh (2004). Leachate treatment by highrate anaerobic reactors of UASB, FBABR and UFAF combined with FBR; En: TC Phát trien khoa hec - công nghe, Vol 7, No 8, pp. 50-57.

[8] Corporación Autónoma Regional de Nariño Corponariño (2004). Registro de parámetros contaminantes encontrados en el sector de trapiches 2002-2004. Pasto. Corponariño.

[9] CRITES, Ron y TCHOBANOGLOUS, George (2000). Tratamiento de aguas residuales en pequeñas poblaciones. Bogotá. Mc. Graw Hill Interamericana S.A. 450 p. 
[10] Departamento Administrativo Nacional de Estadística DANE. (2005). Informe de Necesidades Básicas Insatisfechas -Censo Nacional 2005- Departamento de Nariño. Bogotá. DANE.

[11] ESPAÑA, J; MIRANDA, A. y MORA, E. Proyecto Regional de Comercialización de la panela en el occidente de Nariño; San Juan de Pasto, 1994. Trabajo de grado (Especialización en Proyectos de Desarrollo). Universidad de Nariño-ESAP.

[12] Global Ecolabelling Network GEN. (2006). Product categories of Ecolabelling Programs Worldwide. Página consultada el 15 de agosto del 2006 En: http: www.globalecolabelling. net

[13] GONZALES, Jorge; VALDES, Pedro, NIEVES, Gertrudis y GUERRERO, Barbarita. (1994). Aplicación de la digestión anaerobia a los residuales de industrias lácteas; En: Revista Internacional de Contaminación Ambiental [en línea] 1994, 10 ISSN 0188-4999.

[14] Guía para empresarios GPE (2004). Oportunidades de producción más limpia en la industria panelera. Bogotá.

[15] HELD, Christof; WELLACHER, Martin; ROBRA, Karl-Heinz y GÜBITZ, Georg (2002) Twostage anaerobic fermentation of organic waste in CSTR and UFAF-reactors; En: Bioresource technology, ISSN 0960-8524, Vol. 81, N¹, pp. 19-24

[16] HOBSON, P. y STEWART, C. (1988). The rumen microbial ecosystem. London, England. Elsevier Applied Science. 527 p.

[17] INCE, O; KASAPGIL INCE, B. y DONNELLY, T. (2000). Attachment, strength and performance of a porous media in an upflow anaerobic filter treating dairy wastewater; En: Water science and technology, IWA Publishing, London, Vol.41, ISSN 0273-1223.

[18] LUNA TORRES, E. (1991). Evaluación del proceso de producción de panela en el Departamento de Nariño. Pasto. Universidad de Nariño.

[19] Ministerio de Agricultura de Colombia MAC. (1984). Decreto 1594 del 26 de junio de 1984. Bogotá. MAC.

[20] Ministerio de Desarrollo Económico de Colombia MDEC - Comisión de Regulación de Agua Potable y Saneamiento Básico (2000). Reglamento Técnico del Sector RAS, Resolución 1096 de 17 de noviembre de 2000. Bogotá. MDEC.

[21] NOYOLA, A. (1994). Diseño, inoculación y arranque de reactores UASB; En: Memorias del III Taller y seminario Latinoamericano de Tratamiento anaerobio de aguas residuales. Montevideo, Uruguay. Universidad de la República. 
[22] PAREDES CUERVO, Diego; GUERRERO ERAZO, Jhoniers; CASTAÑO ROJAS, Juan Mauricio (2003). Variaciones al sistema Filtro Anaeróbico de Flujo Ascendente - Humedal de flujo subsuperficial como alternativa de tratamiento de aguas residuales de pequeños y medianos municipios de Colombia. Proyecto investigación UTP.

[23] PRIEUR, D.;GAIL, F. \& CORRE, S. (1993). Complex epibiotic bacterial communities on the marine organisms: fouling or interaction? En: Trends in microbial ecology. Spanish Society for Microbiology, Barcelona, pp. 207-212.

[24] RIVERA, Alejandro; GONZALES, Jorge, CASTRO, Reindaldo; GUERRERO, Barbarita y NIEVES, Gertrudis (2002). Tratamiento de efluentes de destilería en un Filtro anaerobio de flujo ascendente; En: Revista Internacional de Contaminación Ambiental, Vol 18, No.003, pp 131-137

[25] SPEECE, Richard (1996). Anaerobic Biotechnology for Industrial Wastewaters. Tennesse. Vanderbilt University. Archae Press.

[26] TORRES, Patricia; RODRÍGUEZ, Jenny y URIBE, Iris Eugenia (2003). Tratamiento de aguas residuales del proceso de extracción de almidón de yuca en filtro anaerobio: influencia del medio de soporte; En: Scientia et Technica Año IX, No 23, ISSN 0122-170175

[27] Unidad Regional de Planificación Agropecuaria URPA (1983). Diagnóstico agropecuario de Nariño. Pasto.

[28] VILLEGAS GOMEZ, Juan David; GUERRERO ERAZO, Jhonniers; CASTAÑO ROJAS, Juan Mauricio y PAREDES CUERVO, Diego (2006). Septic Tank (ST) - Up Flow Anaerobic Filter (UFAF) - Subsurface Flow Constructed Wetland (SSF$\mathrm{CW}$ ) systems aimed at wastewater treatment in small localities in Colombia; En: Revista Técnica de la Facultad de Ingeniería Universidad del Zulia, ISSN 02540770, V.29, №3.

[29] VILORIA DE LA HOZ, J. (2007). Economía del Departamento de Nariño: ruralidad y aislamiento geográfico; En: Documentos de trabajo sobre economía regional, No. 87, Banco de la República, Centro de Estudios Económicos Regionales CEER, ISSN 1692-3715.

[30] ZEGERS, F. (1987). Descomposición anaerobia de materia orgánica; En: Memorias del curso Arranque y operación de Sistemas UASB. Cali. Universidad Agrícola de Wageningen-Holanda. 
red that the two analytical methodologies are suitable for estimating vibration periods of this type of structures. Just as it was expected, the results of the finite element method are closer to the experimental findings. Also, vibration periods achieved with the wide column method are higher than the experimental ones.

Key words: vibration period, concrete walls, ambient vibration test, numeric models, wide column method, finite elements.

\section{INTRODUCCIÓN}

La estimación del periodo natural de vibración de una estructura de concreto reforzado es un procedimiento esencial en el diseño sísmico. A partir de esta característica puede obtenerse una buena apreciación de las demandas globales sobre una estructura sometida a una determinada acción sísmica. Esta propiedad depende de la masa y la rigidez de la estructura, y es afectada por muchos factores tales como la regularidad de la estructura, el número de pisos y claros, las dimensiones de las secciones, el nivel de carga axial, las cuantías de refuerzo y del nivel de agrietamiento del concreto.

Para determinar los periodos de vibración de viviendas de muros de concreto se utilizan comúnmente ecuaciones simplificadas (Chopra y Goel, 2000; Chun et al., 2000; Goel y Chopra, 1998; Aristizabal-Ochoa, 1983; entre otras), o en el mejor de los casos se construyen modelos numéricos en los cuales se consideran ciertas hipótesis en algunos aspectos estructurales. Sin embargo, existen grandes incertidumbres del comportamiento real ante excitaciones dinámicas, entre los que se destacan los efectos de interacción suelo-estructura, los efectos de torsión, la flexibilidad del diafragma de piso, la efectividad de las juntas constructivas y la participación de elementos no estructurales. El considerar en forma errónea la participación de estos aspectos estructurales puede conducir a estimaciones poco confiables de los periodos de vibración y amortiguamientos naturales de las edificaciones, parámetros importantes que gobiernan la respuesta dinámica de las mismas (Muriá et al., 2000; Muriá y González, 1995).

Con el propósito de estudiar el comportamiento de los muros de concreto de baja altura ante acciones sísmicas, se desarrolló un extenso programa de investigación entre el Instituto de Ingeniería de la UNAM y el Grupo CEMEX de México (Carrillo y Alcocer, 2008, 2008a). Como parte de dicho proyecto se estudió la efectividad de algunas técnicas de modelación numérica como herramientas para calcular los periodos de vibración de viviendas de baja altura a base de muros de concreto. Para ello se llevaron a cabo pruebas experimentales de vibración ambiental y se realizaron modelos numéricos en varias configuraciones típicas de vivienda (Carrillo, 2009). A partir de los resultados obtenidos, en el artículo se establecen las limitaciones y bondades de las técnicas de modelación numérica utilizadas, y se discuten algunos de los parámetros recomendados en los reglamentos para el diseño de este tipo de estructuras. 


\section{TÉCNICAS DE IDENTIFICACIÓN}

Para estimar los periodos de vibración de estructuras es posible utilizar dos técnicas de identificación: (a) técnicas no paramétricas que consisten en determinar las características del sistema estructural con base en análisis espectrales convencionales de pruebas de vibración ambiental y, (b) técnicas paramétricas donde se establece un modelo numérico simplificado y se estiman los valores de los parámetros estructurales necesarios para producir una buena correlación entre la respuesta medida y la calculada.

\subsection{TÉCNICAS PARAMÉTRICAS: MODELACIÓN NUMÉRICA}

Para el intervalo del comportamiento elástico lineal, las deformaciones de un muro ante cierto caso de cargas en su plano, deben calcularse con los métodos y teorías de la elasticidad. Para esto, es necesario tener en cuenta las propiedades elásticas del material, la magnitud y distribución de las cargas, la geometría del muro y la forma en que esté apoyado. Existen diferentes soluciones dependiendo del nivel de complejidad de la geometría o las condiciones de frontera.

El método de la columna ancha (MCA), es uno de las soluciones más aproximadas para el análisis de estructuras a base de muros. Consiste en concentrar las propiedades de los muros (o segmentos de muro) en columnas ficticias ubicadas en el centro de los mismos (eje), las cuales tendrán las características geométricas del muro que representan (figura 1a).

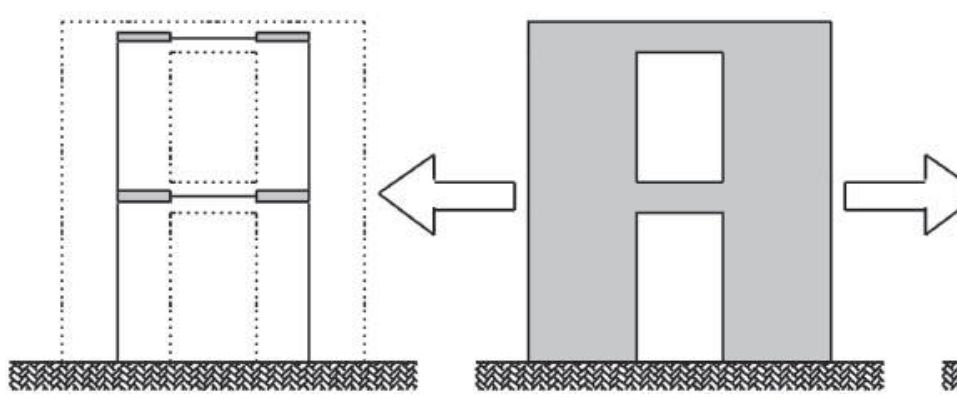

(a) MCA

Figura 1. Aplicación de métodos numéricos.

El método tiene la ventaja de que este tipo de sistemas se idealizan como estructuras esqueletales, lo mismo que los pórticos (Bazán y Meli, 1992; Flores y Alcocer, 2001). Hoy en día, el método del elemento finito (MEF), constituye una de las más poderosas herramientas para el análisis de estructuras complejas, como ciertos muros de composición y geometría complicada (Bazán E. y Meli R., 2004). El MEF constituye un método numérico destinado a resolver, mediante ecuaciones matriciales, las ecuaciones diferenciales que se plantean en sistemas discretos (estructuras) o continuos (campos). En 
programas de computador se toma la geometría planteada y se convierte en un modelo con cierta cantidad definida de elementos (figura 1b).

\subsection{TÉCNICA NO PARAMÉTRICA: PRUEBAS DE VIBRACIÓN AMBIENTAL}

Actualmente existen tres tipos de pruebas experimentales para determinar las características dinámicas de las estructuras en escala real. Una de ellas basada en vibraciones del tránsito de vehículos, del empuje del viento y del uso de la estructura, denominada prueba de vibración ambiental (PVA). Otra metodología son las pruebas de vibración forzada (PVF), en la cual la estructura es excitada por una vibración constante con uno o más motores de vibración que tienen un control de velocidad preciso. Otro método, denominado prueba con registros sísmicos (PRS), consiste en registrar por medio de acelerógrafos los movimientos provocados por los sismos.

La principal diferencia de este tipo de pruebas es la amplitud del movimiento utilizada para determinar las características dinámicas de la estructura. Por ejemplo, las PRS tienen la ventaja de poder estudiar el comportamiento dinámico de estructuras cuando éstas se someten a amplitudes de excitación mucho mayor que las que se presentan con ruido ambiental (Muriá y González, 1995).

Adicionalmente, debido a las características de los equipos, el número de instrumentos y el tiempo que se requiere para realizar estos tipos de pruebas, la inversión económica en cada una de ellas difiere apreciablemente. Por ejemplo, realizar una PVF puede requerir mayor inversión económica que la necesaria para efectuar una PVA (Trifunac, 1972). Debido a que no se conoce la fecha de ocurrencia de un movimiento sísmico, podría ser necesario ubicar por un tiempo prolongado los instrumentos requeridos para realizar una PRS, por lo cual, su costo puede ser uno de los más elevados.

En las pruebas de vibración ambiental (PVA), a través de acelerómetros de alta resolución, se registran las vibraciones producidas en las estructuras debido a condiciones ambientales, por lo que es un método simple y rápido en la obtención de datos, con la ventaja de no interferir en las actividades normales que se realizan en los inmuebles. Las señales captadas por los acelerómetros son transmitidas a unos acondicionadores donde se amplifican y se filtran con el fin de obtener registros claros y adecuados. Empleando diferentes arreglos de acelerómetros que se localizan en puntos de medición seleccionados, es posible determinar las principales propiedades dinámicas de una estructura, entre ellas, sus periodos de vibración.

\subsubsection{Equipo utilizado}

Para este estudio se utilizó un sistema de adquisición de datos que permite capturar simultáneamente las vibraciones en ocho puntos de la estructura. En cada punto de medición elegido se coloca un servo-acelerómetro de alta resolución para detectar y 
adquirir las señales de ruido ambiental, cuyas amplitudes son entre 10-4 a 10-5 g, en un tiempo de captura de aproximadamente 10 minutos. Estas señales son trasmitidas, a través de cables blindados, a unos acondicionadores donde se amplifican y se filtran las frecuencias mayores que $30 \mathrm{~Hz}$. Las señales acondicionadas se envían a una microcomputadora en donde se almacena toda la información. Se cuenta con un analizador de espectros de dos canales, con el cual se monitorea la evolución de los espectros durante la prueba (Figura 2).

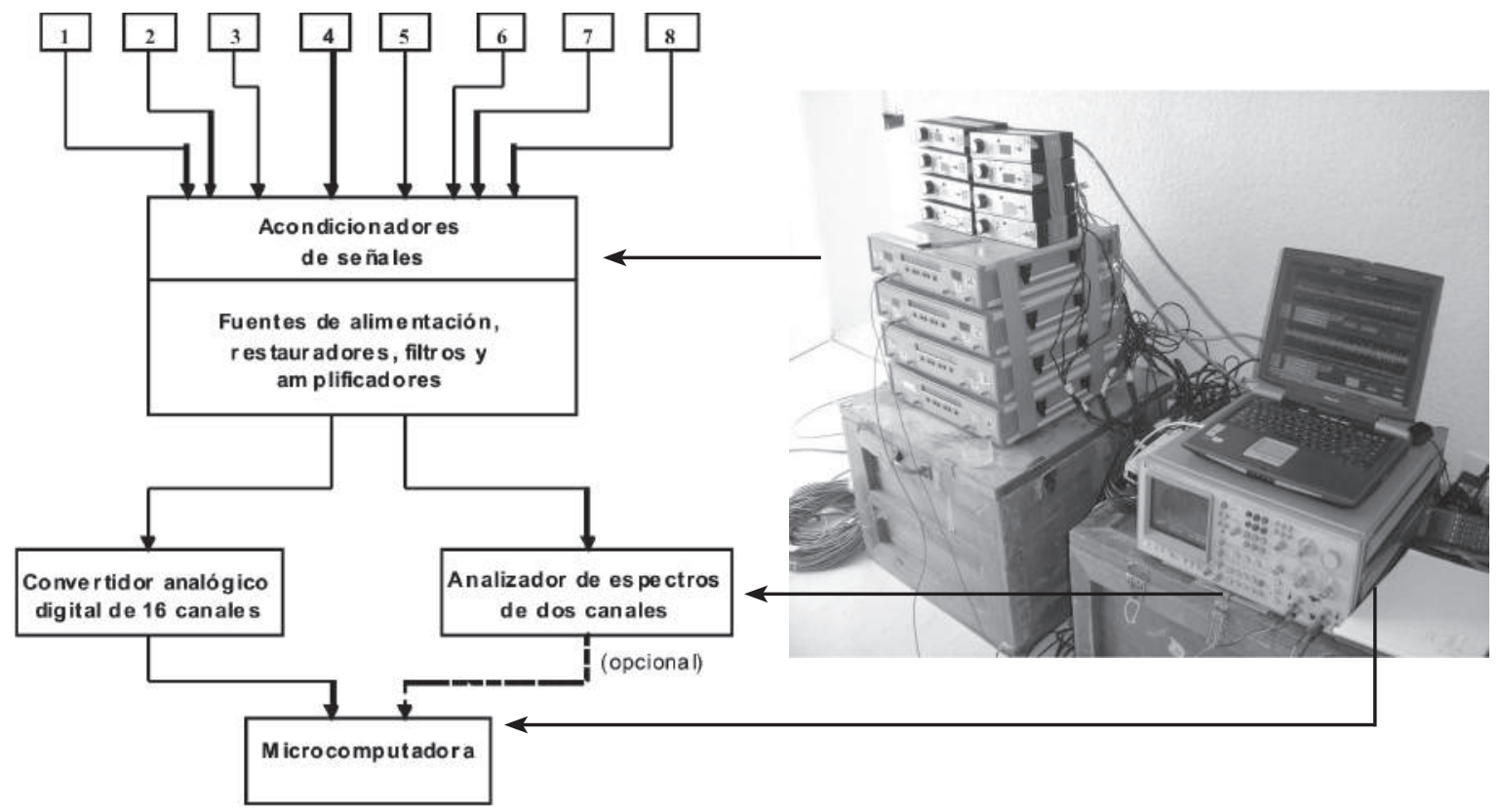

Figura 2. Diagrama de flujo del dispositivo experimental.

\subsubsection{Interpretación de resultados}

El procesamiento de la información consistió en un análisis de señales aleatorias estacionarias para obtener los espectros de densidad espectral, así como las correspondientes funciones de transferencia (en fase y amplitud) y de coherencia entre pares de señales. Para identificar las frecuencias naturales de vibración se utilizó tanto el espectro de potencia promedio y la función de transferencia como la de coherencia. De lo contrario, podrían cometerse errores si se utilizan exclusivamente los espectros de Fourier, debido a la presencia de otras ordenadas espectrales que pueden ser significativas pero ajenas a las frecuencias naturales de la edificación como son, por ejemplo, las ordenadas asociadas a vibraciones de estructuras vecinas y de equipo electromecánico (Muriá, 1997). Para identificar las frecuencias traslacionales de vibración fue necesario utilizar los espectros de potencia promedio. Lo anterior debido a que las edificaciones analizadas son de muy bajo periodo (alta rigidez y baja altura) y están 
desplantadas sobre suelo firme, lo cual genera un movimiento de cuerpo rígido que dificulta la identificación de las frecuencias propias de la estructura a partir de la función de transferencia. Sin embargo, para identificar la frecuencia de vibración rotacional se utilizó la función de transferencia en fase y amplitud, ya que las señales son adquiridas en puntos que hacen parte de la estructura.

\section{VIVIENDAS ANALIZADAS}

Para realizar la comparación de las técnicas de identificación se realizaron modelos numéricos y pruebas de vibración ambiental en diferentes configuraciones de viviendas de baja altura con muros de concreto. La modelación numérica se realizó en estructuras de uno y dos niveles. Debido a inconvenientes logísticos (ocupación de las viviendas por los usuarios), sólo fue posible realizar pruebas de vibración ambiental en tres viviendas de un nivel. A partir de los resultados experimentales en las viviendas de un nivel, se calibraron los modelos numéricos de las viviendas de uno y dos niveles.

\subsection{VIVIENDAS DE UN NIVEL}

\subsubsection{Descripción general vivienda tipo I}

Corresponde a una vivienda de interés social con muros de $10 \mathrm{~cm}$ de espesor, resistencia nominal a la compresión del concreto, fc' = $14.7 \mathrm{MPa}(150 \mathrm{kgf} / \mathrm{cm} 2)$ y módulo de elasticidad de $9600 \mathrm{MPa}(98000 \mathrm{kgf} / \mathrm{cm} 2)$. Las dimensiones globales de la vivienda entre ejes son de $5.8 \mathrm{~m}$ x $10.4 \mathrm{~m}$ (Figura 3), y tienen un área aproximada de $50 \mathrm{~m} 2$. En la losa de azotea sobresale una estructura que sirve para el almacenamiento de un tanque de agua con capacidad máxima de $1 \mathrm{~m} 3$. La configuración de estas viviendas se muestra en la Figura 4. La cimentación está conformada por vigas en las dos direcciones de $40 \mathrm{~cm}$ de base y de altura, y una losa de concreto de $10 \mathrm{~cm}$ de espesor. La cimentación fue calculada para una capacidad portante del terreno de $0.15 \mathrm{MPa}$ (15 $\mathrm{tf} / \mathrm{m} 2)$. La altura libre de los muros es de $2.4 \mathrm{~m}$.

\subsubsection{Descripción general vivienda tipo 2}

Corresponde a dos prototipos de viviendas construidas en el Centro de Tecnología del Cemento y del Concreto (CTCC) de CEMEX en México. Las dos viviendas tienen un área aproximada de $36 \mathrm{~m} 2$ (ver Figura 5), muros con espesor de $10 \mathrm{~cm}$ y altura libre de $2.4 \mathrm{~m}$. Las viviendas fueron construidas con concreto de resistencia nominal a la compresión de 14.7 MPa (150 kgf/cm2), una de ellas con concreto normal y la otra con concreto celular (ver Figura 6). La losa de la azotea se divide en dos tipos: la mitad de la vivienda tiene una losa maciza de $10 \mathrm{~cm}$ de espesor y la otra mitad, una losa aligerada en una dirección con viguetas separadas cada $60 \mathrm{~cm}$, casetón de poliestireno de $10 \mathrm{~cm}$ y losa de compresión de $5 \mathrm{~cm}$. 


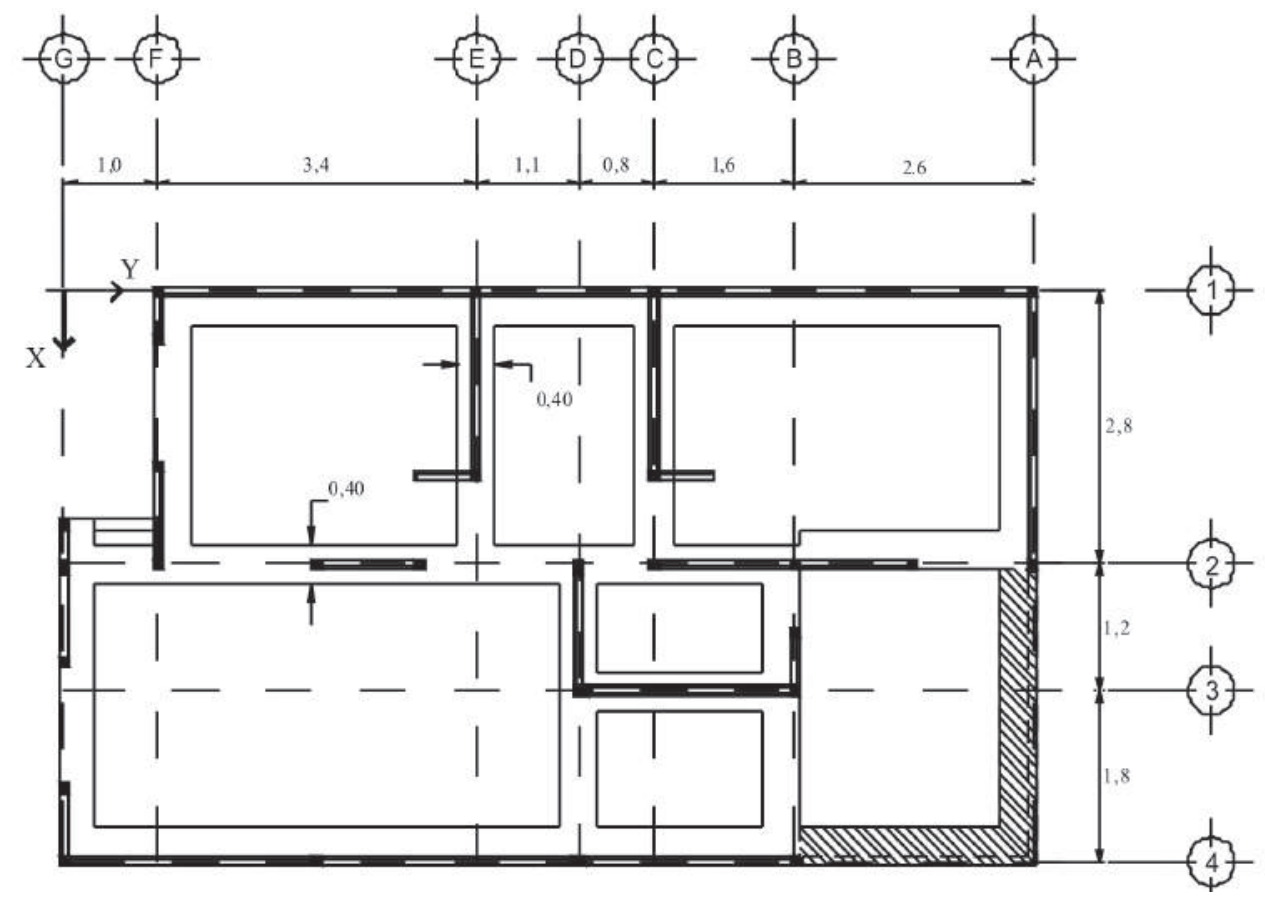

Figura 3. Planta de cimentación y de muros de la vivienda Tipo 1 de un nivel (acotaciones en m)
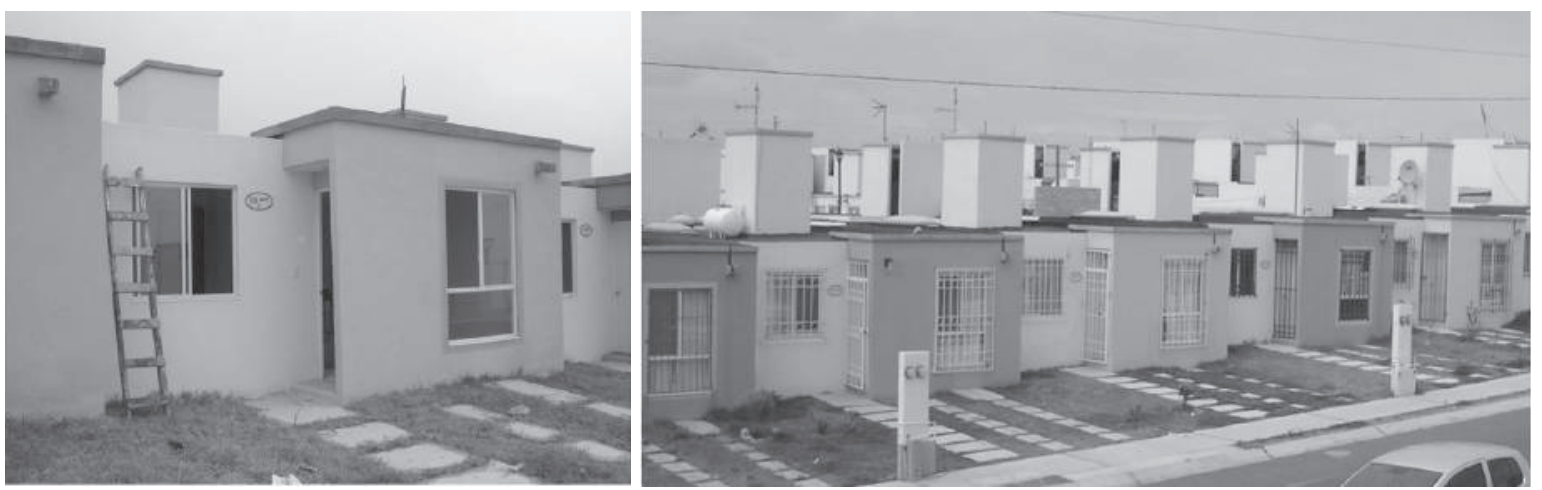

Figura 4. Configuración de las viviendas Tipo 1 de un nivel.

\subsubsection{Parámetros de modelación}

Para realizar la modelación elástica con el MCA y el MEF, se utilizó el Programa SAP2000 V10.01 (Computer and Structures, 2005). Para la evaluación de cargas (y masas) se siguieron las recomendaciones estipuladas en las Normas Técnicas Complementarias sobre Criterios y Acciones (NTC-Cr, 2004) y para diseño por Sismo (NTC-S, 2004) del Distrito Federal de México. Debido a que las viviendas se encuentran actualmente en uso, en la modelación se tuvo en cuenta la presencia de regiones fisuradas por medio de la modificación de las propiedades de los elementos, recurriendo a la recomenda- 
ción estipulada en la sección 1.4.1 de las NTC-C (2004), es decir, utilizando el 50\% de la inercia gruesa de las secciones $(0.5 \mathrm{lg})$. Las losas de entrepiso se modelaron por medio de diafragmas rígidos, donde se ubicaron los centros de masa y se aplicaron las masas traslacionales y rotacionales correspondientes.

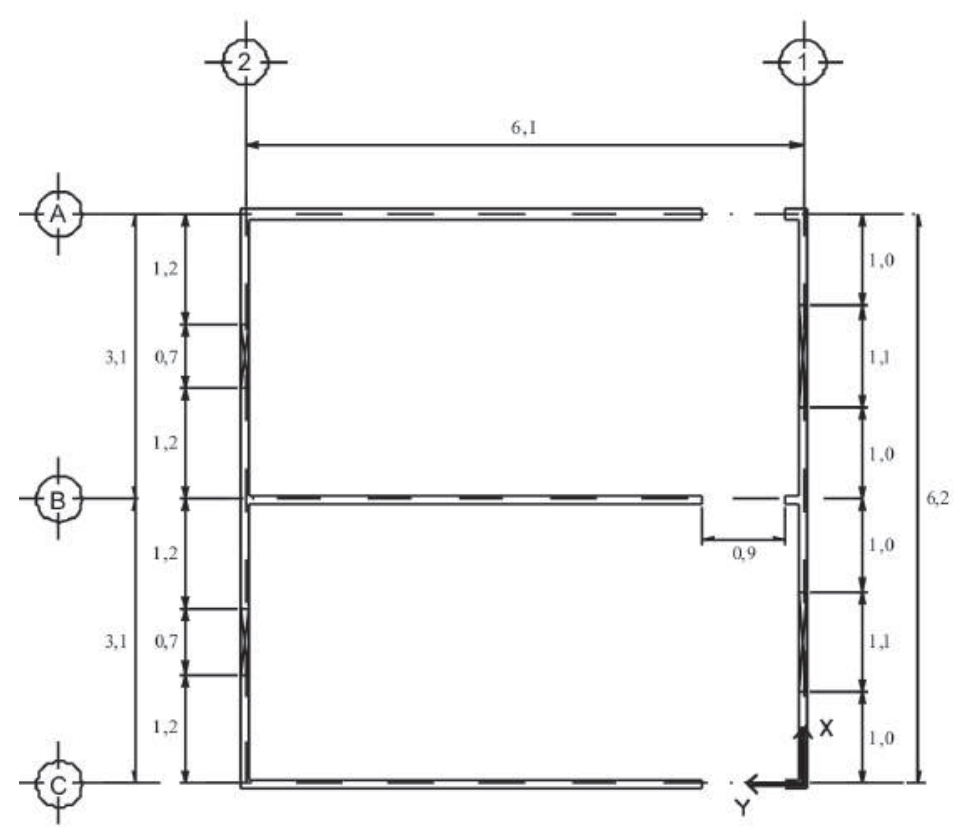

Figura 5. Planta de muros de las viviendas Tipo 2 de un nivel (acotaciones en $\mathrm{m}$ )

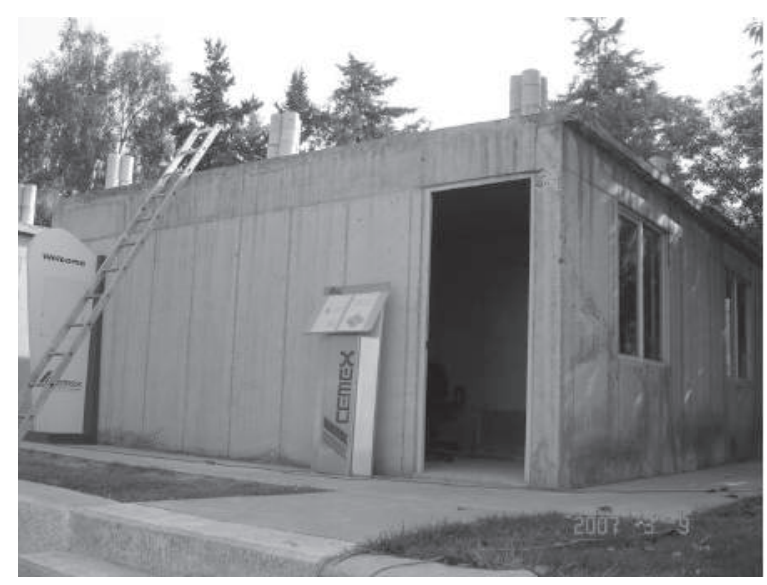

(a) En concreto normal

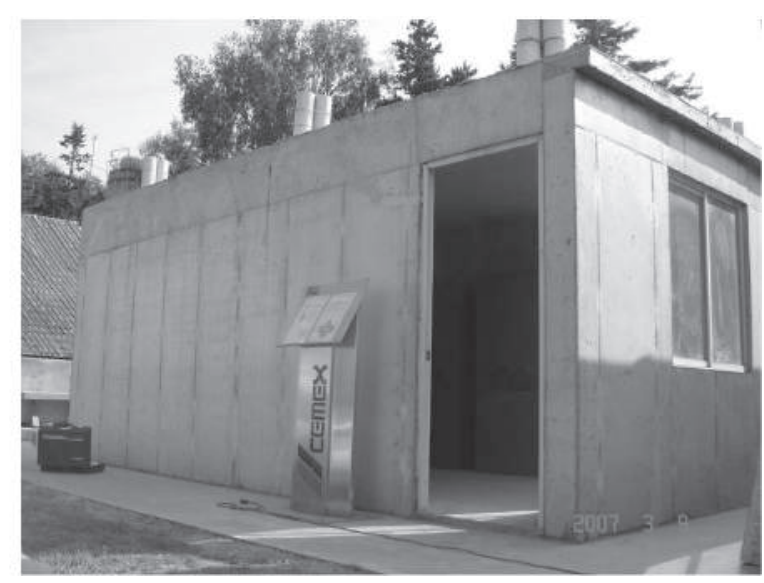

(b) En concreto celular

Figura 6. Configuración de las viviendas Tipo 2 de un nivel

Para tener en cuenta el efecto del tipo de suelo y de la cimentación de las viviendas, se modeló la interacción suelo-estructura utilizando rigideces equivalentes por medio del 
módulo de reacción del suelo (Bazán y Meli, 2004). Para esto, fue necesario modelar la losa de cimentación por medio de elementos finitos conectados por un diafragma rígido. Debido a que no se realizó un estudio geotécnico para determinar el módulo de reacción del suelo, se utilizaron valores promedio disponibles en la literatura en función del tipo y la clasificación del suelo. Para la vivienda Tipo 1 se supuso un módulo de reacción vertical del suelo, Ksv, igual a 50000 kN/m3 (5100 tf/m3). Para las viviendas Tipo 2 se supuso un módulo igual a $40000 \mathrm{kN} / \mathrm{m} 3$ (4100 tf/m3). En la dirección horizontal, para los dos tipos de viviendas, se utilizó el 30\% del módulo en la dirección vertical. A partir del área aferente a cada uno de los nodos de la losa de cimentación, se asignaron las rigideces equivalentes en las tres direcciones por medio de elementos tipo resorte.

Vivienda Tipo 1. En la modelación se utilizaron las características mecánicas nominales del concreto. Dichas propiedades se encuentran en el intervalo de medición obtenido a partir de pruebas no destructivas (equipo de esclerómetro y ultrasonido) realizadas a los muros durante la visita de campo (IMCYC, 2007). La mayoría de estas viviendas son construidas una al lado de otra, separadas por medio de una junta conformada por una lámina de poliestireno. Sin embargo, dicha junta no funciona adecuadamente ya que durante la construcción, se obstruye parcialmente con residuos de concreto. Para tener en cuenta el efecto de la junta en la modelación, se asignaron rigideces equivalentes (aproximadas) a elementos tipo resorte ubicados en los dos costados de la vivienda donde se habilita la junta. Los modelos se muestran en la Figura 7.

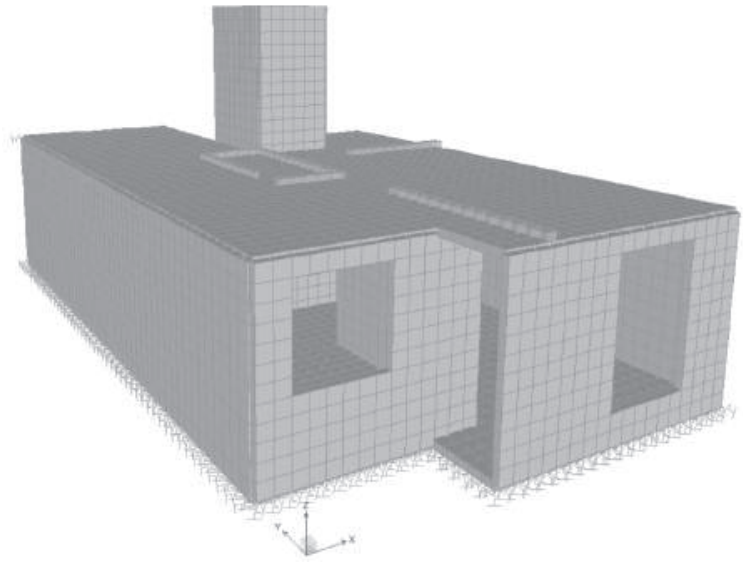

(a) MEF

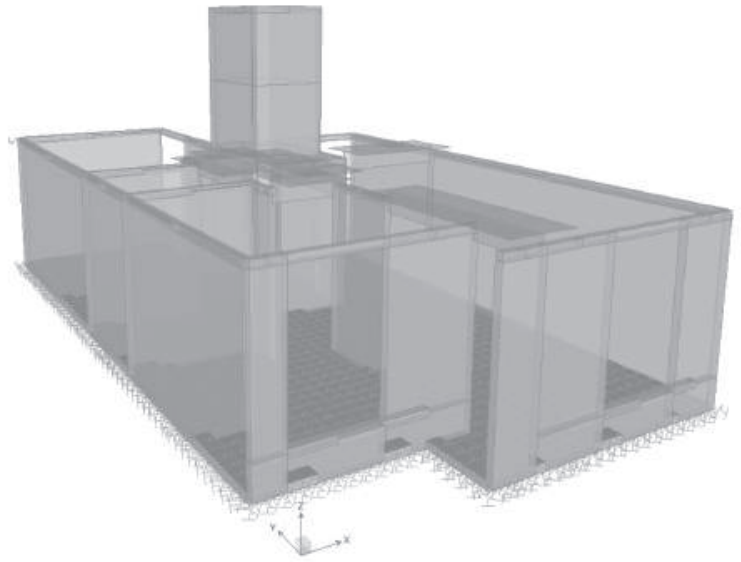

(b) MCA

Figura 7. Geometría general de los modelos de análisis de la vivienda Tipo 1 de un nivel

Viviendas Tipo 2. Las propiedades mecánicas del concreto utilizadas en la modelación fueron obtenidas experimentalmente a partir del ensaye de núcleos extraídos a los muros. Para la vivienda de concreto normal la resistencia a la compresión fue de 19.5 MPa (200 kgf/cm2) y un módulo de elasticidad de 12250 MPa (125000 kgf/cm2). Para 
la vivienda de concreto celular, estos valores fueron de $44.6 \mathrm{MPa}(455 \mathrm{kgf} / \mathrm{cm} 2)$ y de $20483 \mathrm{MPa}$ (209000 kgf/cm2). Los modelos de análisis se muestran en la Figura 8.
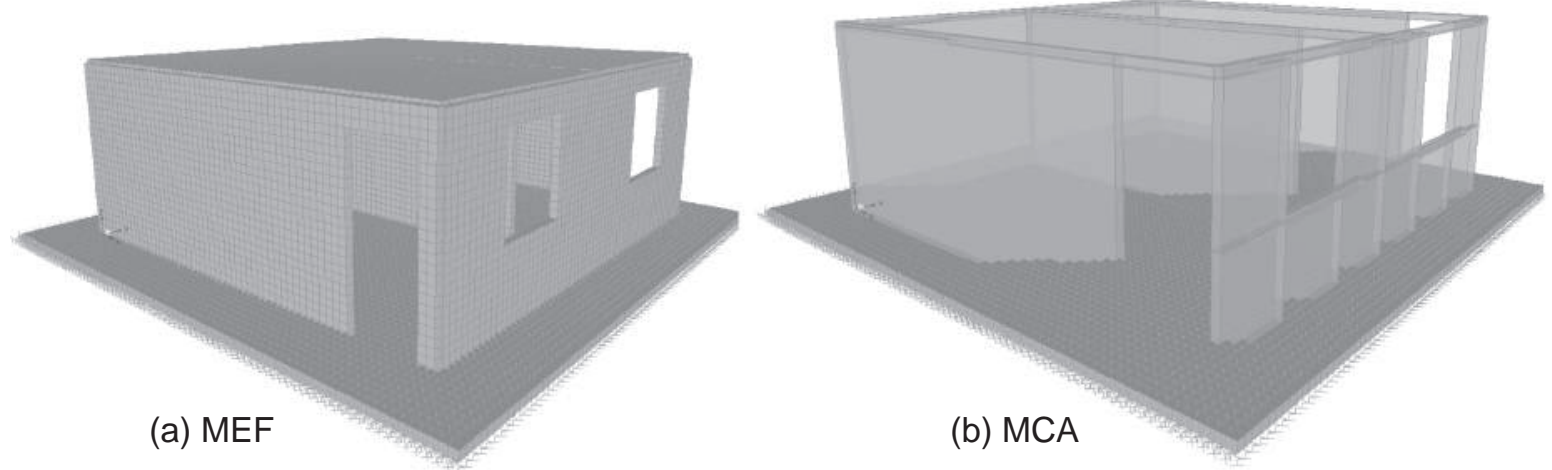

Figura 8. Geometría general de los modelos de análisis de las viviendas Tipo 2 de un nivel

\subsubsection{Pruebas de vibración ambiental}

Como se mencionó anteriormente, sólo fue posible realizar pruebas de vibración ambiental en las viviendas de un nivel. Sin embargo, los resultados obtenidos fueron esenciales para la calibración de los modelos numéricos tanto de las viviendas de uno, como de dos niveles.

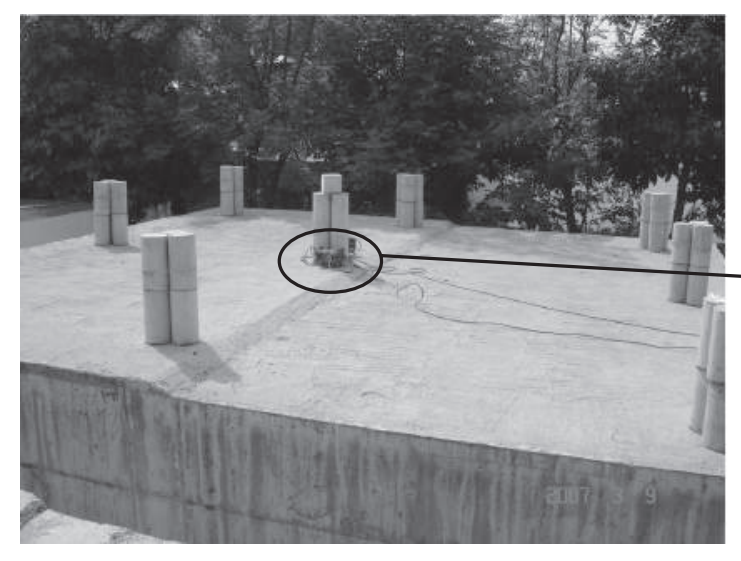

(a) Vista general

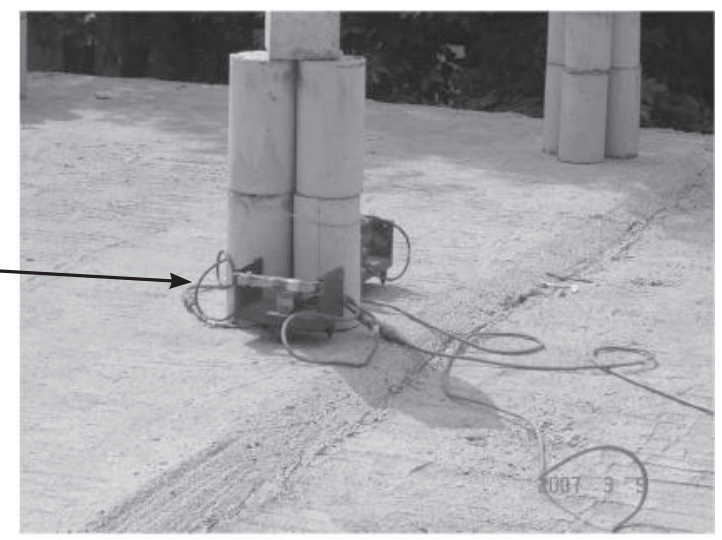

(b) Detalle

Figura 9. Ubicación en acelerómetros en la azotea de una vivienda

Descripción general de las pruebas. Las pruebas consistieron en colocar y orientar los acelerómetros cerca de los centros geométricos de los dos niveles de la estructura en sus direcciones ortogonales, las cuales se identificaron como T y L (Transversal y Longitudinal). La dirección $T$ corresponde a la dirección del eje $X$ y la dirección $L$ a la dirección del eje Y, de la Figura 3 (vivienda Tipo 1) y de la Figura 5 (vivienda Tipo 2). Se ubicaron 
dos acelerómetros en la azotea $(A C)$, dos en la planta del primer nivel y otros dos en un punto en el terreno (CL). Posteriormente, los acelerómetros de la azotea se movieron a las esquinas opuestas para determinar el modo de vibración de torsión (ver Figura 9).

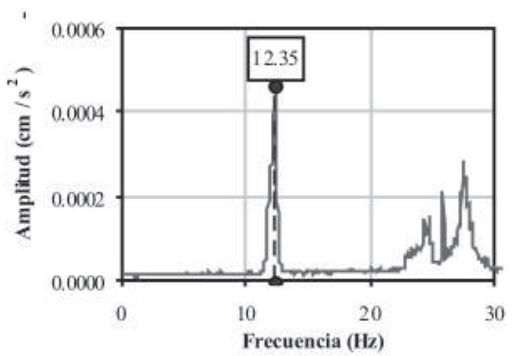

(a) EPP, $A C(T)$

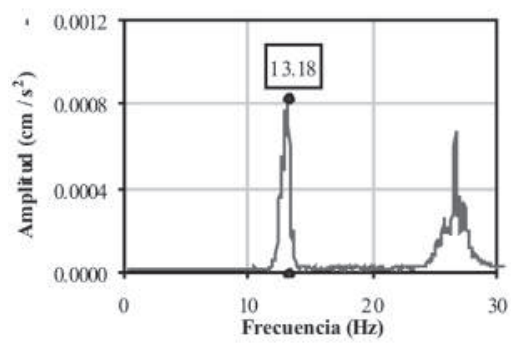

(b) EPP, $A C(L)$

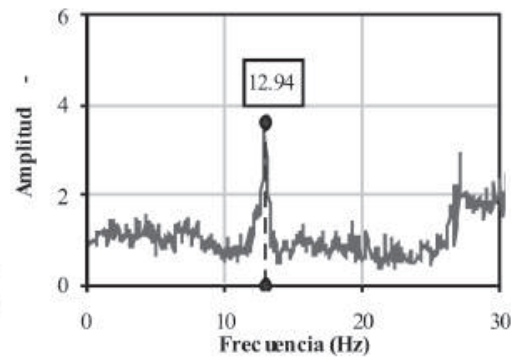

(c) FT, AC(T) / AC(L)

Figura 10. Resultados de la prueba en la vivienda Tipo 1

Procesamiento de la información. En la Figura 10 se presentan los espectros de potencia promedio (EPP) para identificar las frecuencias naturales de vibración en la dirección transversal y longitudinal, y la función de transferencia (FT) para establecer la frecuencia asociada al modo de vibración de torsión en la vivienda. En los recuadros de cada gráfica se presenta la frecuencia de vibración. En la Figura 11 y en la Figura 12 se presentan los resultados para la vivienda construida en concreto normal y la de concreto celular, respectivamente.

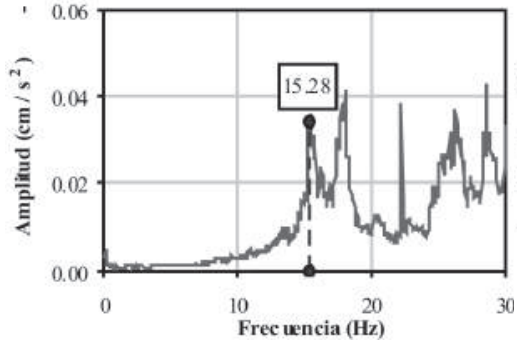

(a) EPP, AC(T)

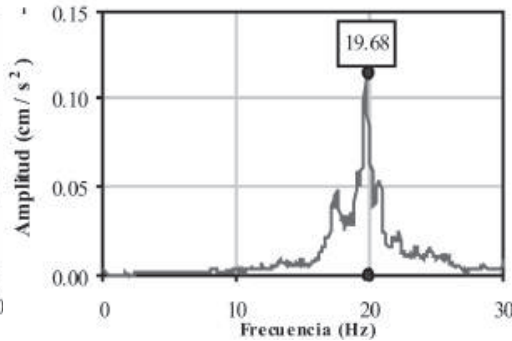

(b) EPP, AC(L)

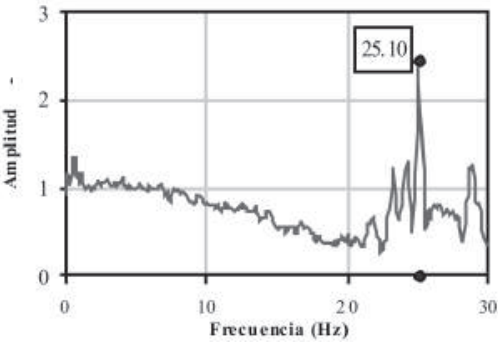

(c) FT, AC(T) / AC(L)

Figura 11. Resultados de la prueba en la vivienda Tipo 2 de concreto normal

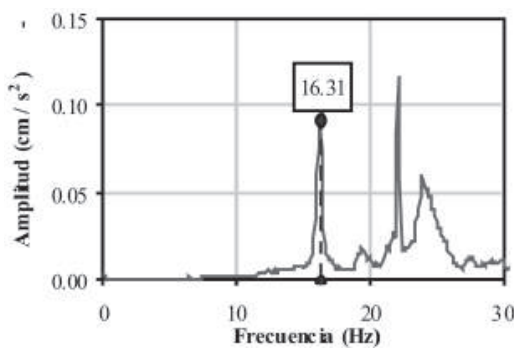

(a) EPP, AC(T)

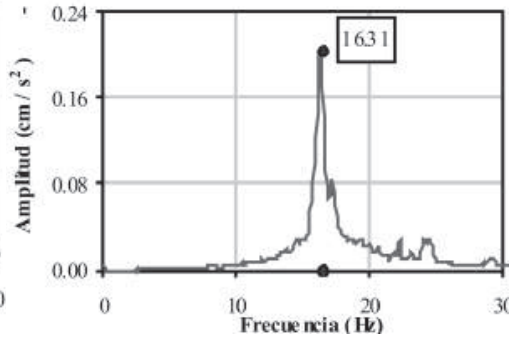

(b) EPP, AC(L)

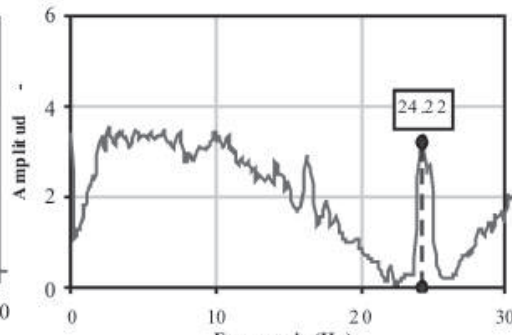

(c) $\mathrm{FT}, \mathrm{AC}(\mathrm{T}) / \mathrm{AC}(\mathrm{L})$

Figura 12. Resultados de la prueba en la vivienda Tipo 2 de concreto celular. 


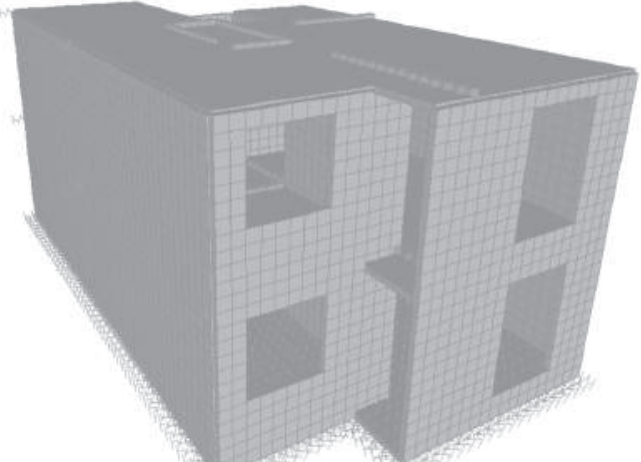

(a) MEF

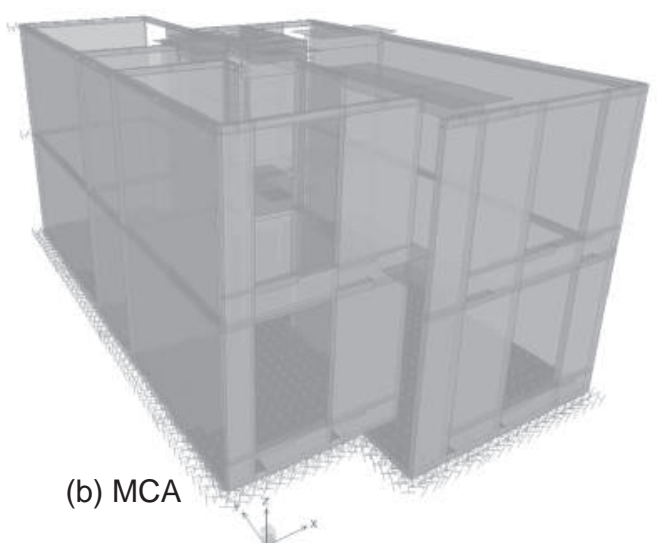

(b) MCA

Figura 13. Geometría general de los modelos de análisis de la vivienda de dos niveles.

\subsection{VIVIENDAS DE DOS NIVELES}

Corresponden a viviendas Tipo 1 de un nivel, en las cuales se prolonga la construcción hasta el segundo nivel. Por lo tanto, las características generales, la evaluación de cargas (y masas) y los demás parámetros de modelación (interacción suelo-estructura, junta entre las viviendas, etc.) son similares a las de las viviendas de un nivel. En la Figura 13 se muestran los modelos numéricos.

\section{RESULTADOS Y DISCUSIÓN}

VIVIENDAS DE UN NIVEL. En la Tabla 1 se presentan los periodos de vibración obtenidos a partir de la modelación numérica y de las pruebas de vibración ambiental de la vivienda Tipo 1. En la Tabla 2 y en la Tabla 3 se presentan los resultados para las viviendas Tipo 2 de concreto normal y celular, respectivamente. En estas tablas se presenta la relación entre los periodos analíticos y experimentales (TMEF/TPVA y TMCA/TPVA), al igual que la relación entre los periodos calculados con las metodologías numéricas (TMEF/TMCA).

Tabla 1. Periodos de vibración en la vivienda Tipo 1.

\begin{tabular}{|c|c|c|c|c|c|c|}
\hline \multirow{2}{*}{ Modo ${ }^{1}$} & \multicolumn{3}{|c|}{$\mathrm{T}(\mathrm{s})$} & \multirow{2}{*}{$\mathbf{T}_{\mathrm{MEF}} / \mathrm{T}_{\mathrm{PVA}}$} & \multirow{2}{*}{$T_{\text {MCA }} / T_{\text {PVA }}$} & \multirow{2}{*}{$T_{\text {MEF }} / T_{\text {MCA }}$} \\
\hline & PVA $^{2}$ & MEF $^{3}$ & MCA $^{4}$ & & & \\
\hline $\mathrm{T}$ & 0.081 & 0.081 & 0.089 & 1.00 & 1.10 & 0.92 \\
\hline L & 0.076 & 0.073 & 0.094 & 0.96 & 1.23 & 0.77 \\
\hline $\mathrm{R}$ & 0.077 & 0.041 & 0.045 & 0.53 & 0.58 & 0.91 \\
\hline
\end{tabular}

Notas:

1. Dirección del modo de vibración: T (Transversal: eje X), L (Longitudinal: eje Y) y R (Rotacional)

2. Prueba de Vibración Ambiental

3. Método de Elementos Finitos

4. Método de la Columna Ancha 
Tabla 2. Periodos de vibración en la vivienda Tipo 2 de concreto normal.

\begin{tabular}{|c|c|c|c|c|c|c|}
\hline \multirow{2}{*}{ Modo } & \multicolumn{3}{|c|}{$T(s)$} & \multirow{2}{*}{$\mathrm{T}_{\text {MEF }} / \mathrm{T}_{\text {PVA }}$} & \multirow{2}{*}{$\mathrm{T}_{\text {MCA }} / \mathrm{T}_{\mathrm{PVA}}$} & \multirow{2}{*}{$\mathbf{T}_{\text {MEF }} / \mathbf{T}_{\text {MCA }}$} \\
\hline & PVA & MEF & MCA & & & \\
\hline $\mathrm{T}$ & 0.065 & 0.066 & 0.083 & 1.02 & 1.26 & 0.80 \\
\hline L & 0.051 & 0.055 & 0.072 & 1.09 & 1.42 & 0.77 \\
\hline $\mathrm{R}$ & 0.040 & 0.035 & 0.039 & 0.88 & 0.99 & 0.89 \\
\hline
\end{tabular}

Tabla 3. Periodos de vibración en la vivienda Tipo 2 de concreto celular.

\begin{tabular}{|c|c|c|c|c|c|c|}
\hline \multirow{2}{*}{ Modo } & \multicolumn{3}{|c|}{$\mathbf{T}(\mathbf{s})$} & \multirow{2}{*}{$\mathbf{T}_{\text {MEF }} / \mathbf{T}_{\text {PVA }}$} & \multirow{2}{*}{$\mathbf{T}_{\text {MCA }} / \mathbf{T}_{\text {PVA }}$} & $\mathbf{T}_{\text {MEF }} / \mathbf{T}_{\text {MCA }}$ \\
\cline { 2 - 4 } & PVA & MEF & MCA & 0.94 & 1.17 & 0.81 \\
\hline$T$ & 0.061 & 0.058 & 0.071 & 0.94 & 17 \\
\hline $\mathrm{L}$ & 0.061 & 0.049 & 0.065 & 0.81 & 1.06 & 0.76 \\
\hline $\mathrm{R}$ & 0.041 & 0.032 & 0.036 & 0.77 & 0.86 & 0.89 \\
\hline
\end{tabular}

En cuanto al periodo de vibración fundamental (primer modo) en las dos metodologías numéricas utilizadas, la relación entre el periodo analítico y experimental (TMEF/TPVA y TMCA/TPVA), es adecuada. Sin embargo, los periodos de vibración obtenidos por medio del MEF son, en general, mucho más cercanos a los de las PVA. Adicionalmente, los periodos de los modelos del MCA son mayores que los del MEF, aproximadamente entre $9(1 / 0.92)$ y $25 \%(1 / 0.80)$ para el periodo fundamental de vibración. Esta última tendencia se esperaba, ya que por medio del MCA no se alcanza a modelar adecuadamente las condiciones de frontera de los muros, especialmente los de mayor longitud. Por lo tanto, teniendo en cuenta la gran cantidad de incertidumbres que existen en la elaboración de modelos numéricos de estructuras, se puede inferir que estas metodologías son aceptables para la modelación de viviendas de muros de concreto. Sin embargo, es importante hacer algunas aclaraciones y comentarios:

- Durante la visita de campo se observó el mal estado de la junta de construcción entre las viviendas Tipo 1 de un nivel. Aunque en los modelos se incluyó el efecto de la junta por medio de elementos tipo resorte con rigideces equivalentes aproximadas, es probable que la irregularidad de las propiedades de la junta a lo largo de su longitud altere las frecuencias de vibración obtenidas con las metodologías numéricas, especialmente la frecuencia de vibración en la dirección transversal.

- Como se mencionó anteriormente, muchos de los sistemas de piso que se utilizan en la construcción de vivienda deben catalogarse como diafragmas flexibles. Tal como lo indica Tena (2007), esta es una condición que debe revisarse, pues la respuesta ante cargas laterales entre una estructura con diafragmas rígidos y otra con diafragmas flexibles puede ser muy diferente. En este estudio no se realizó un análisis detallado de los sistemas de piso y se supuso la condición de diafragma rígido. Sin embargo, para el sistema estructural y los claros de estas viviendas, se considera una suposición apropiada. 
- $\quad$ Además de las incertidumbres asociadas con las características propias de las edificaciones analizadas, los resultados obtenidos también dependen del tipo de excitación que se utilice para determinar las características dinámicas. Lo anterior, ya que la estructura puede experimentar diferentes niveles de esfuerzo y no linealidad de los materiales. La determinación de dichas características a partir de PVA, proporciona información del comportamiento estructural asociado a muy bajas amplitudes de excitación y pueden sufrir variaciones significativas durante sismos intensos debido al comportamiento no lineal y al deterioro de la rigidez de los sistemas estructurales (Muriá y González, 1995). Sin embargo, las propiedades dinámicas determinadas a partir de pruebas de pequeña amplitud son un punto de referencia importante para cálculos más detallados y completos (Trifunac, 1972).

VIVIENDAS DE DOS NIVELES. Los resultados de la pruebas de vibración ambiental de la vivienda Tipo 1 de un nivel, también fueron utilizados para establecer los parámetros de calibración en los modelos numéricos de las viviendas de dos niveles. En la Tabla 4 se muestran los periodos de vibración de la vivienda. De forma similar a los modelos de las viviendas de un nivel, los periodos de vibración obtenidos con el MCA son mayores que los del MEF. Cuando se compararon los resultados analíticos con los experimentales en las viviendas de un nivel, se encontró que los periodos de vibración obtenidos con el MEF son mucho más cercanos a los de las PVA. Por lo tanto, para este tipo de viviendas en particular se considera representativo un periodo fundamental de aproximadamente $0.12 \mathrm{~s}(\approx 8 \mathrm{~Hz})$.

Tabla 4. Periodos de vibración en las viviendas de dos niveles.

\begin{tabular}{|c|c|c|c|}
\hline \multirow{2}{*}{ Modo } & \multicolumn{2}{|c|}{ T (s) } & \multirow{2}{*}{ T $_{\text {MEF }} / \mathbf{T}_{\text {MCA }}$} \\
\cline { 2 - 3 } & MEF & MCA & 0.80 \\
\hline $\mathrm{L}$ & 0.121 & 0.152 & 0.93 \\
$\mathrm{~T}$ & 0.110 & 0.119 & 0.93 \\
$\mathrm{R}$ & 0.062 & 0.066 & 0.93 \\
\hline
\end{tabular}

Teniendo en cuenta las consideraciones realizadas anteriormente, es importante mencionar que los resultados encontrados son un indicio del periodo de vibración de este tipo de viviendas y no deben utilizarse para un diseño definitivo de una estructura en particular. Lo anterior, ya que aunque las construcciones tienen sistemas estructurales similares, la variación de alguna o algunas características como su geometría, niveles de esfuerzo, deterioro, características de los materiales, entre otras; pueden originar una variación importante entre las propiedades dinámicas de edificaciones aparentemente similares.

\section{CONCLUSIONES}

A partir de los resultados obtenidos y teniendo en cuenta las incertidumbres en la elaboración de modelos numéricos, se puede concluir que las dos metodologías numéricas 
estudiadas son aceptables para la modelación de viviendas de muros de concreto de baja altura. Si bien es relativamente sencillo elaborar modelos por medio del MCA, las simplificaciones en la concentración de las propiedades del muro en un elemento tipo "barra" y en el apoyo de estos elementos en un solo punto, originan que los resultados obtenidos sean mayores que los de las PVA. Aunque en la modelación por medio del MEF se tienen en cuenta de una manera más detallada las características geométricas y la condición de apoyo de los muros, también se presentan pequeñas diferencias respecto a las PVA. No obstante, los periodos de vibración obtenidos a partir pruebas de vibración ambiental están asociados a amplitudes de excitación bajas y, por lo tanto, es probable que aumenten durante una excitación sísmica.

\section{AGRADECIMIENTOS}

El autor desea expresar su agradecimiento al Dr. Sergio Alcocer Martínez de Castro, profesor investigador del Posgrado en Ingeniería de la Universidad Nacional Autónoma de México (UNAM), por su asesoría durante el desarrollo de la investigación. Así mismo, al Grupo CEMEX (México) por el patrocinio económico de la investigación y al Grupo de trabajo de la Coordinación de Estructuras y Materiales del Instituto de Ingeniería de la UNAM, es especial al Dr. David Muriá Vila y al M.I. Gerardo Rodríguez, por su colaboración durante la realización de las pruebas de vibración ambiental en las viviendas.

\section{REFERENCIAS BIBLIOGRÁFICAS}

[1] BAZÁN, Enrique y MELI, Roberto (2004). Diseño sísmico de edificios. Editorial Limusa S. A., México.

[2] ARISTIZABAL-OCHOA, Dario. (1983). Cracking and shear effects on structural walls. En: Journal of Structural Engineering - ASCE, Vol. 109, No. 5, pp. 1267-1277.

[3] BAZÁN, Enrique y MELI, Roberto (1992). Manual de diseño sísmico de edificios. Editorial Limusa S. A., México.

[4] CARRILLO, Julián (2009). Evaluación del comportamiento a cortante de muros de concreto para vivienda por medio de ensayes dinámicos. Tesis de Doctorado (en proceso). Universidad Nacional Autónoma de México.

[5] CARRILLO, Julián y ALCOCER, Sergio (2008). Shaking table test of low-rise concrete waIls for housing. 14th World Conference on Earthquake Engineering, Beijing, China, Artículo 12-01-0011.

[6] CARRILLO, Julián y ALCOCER, Sergio (2008a). Ensayes dinámicos de muros de concreto con relación de aspecto igual a uno. XVI Congreso Nacional de Ingeniería Estructural, Veracruz, México. Tema VI, Art. 9. 
[7] CHOPRA, Anil y GOEL, Rakesh (2000). Building period formulas for estimating seismic displacements. En: Journal of Earthquake Spectra, Vol. 16, No. 2, pp. 533-536.

[8] CHUN, Young-Soo; YANG, Ji-Soo; CHANG, Kug-Kwan y LEE, Li-Hyung (2000). Approximate estimations of natural periods for apartment buildings with sehar-wall dominant system. 12th World Conference on Earthquake Engineering, Nueva Zelanda. Artículo 0018.

[9] COMPUTER AND STRUCTURES (2005). Static and dynamic finite element analysis of structures - SAP2000 V10.01. Berkeley, California, USA.

[10] FLORES, Leonardo y ALCOCER, Sergio (2001). Estudio analítico de estructuras de mampostería confinada. Informe Técnico. Coordinación de Investigación - CENAPRED. México.

[11] GOBIERNO DEL DISTRITO FEDERAL (2004). Normas técnicas complementarias sobre criterios y acciones para el diseño estructural de las edificaciones (NTC-Cr). Gaceta Oficial del Distrito Federal. México.

[12] GOBIERNO DEL DISTRITO FEDERAL (2004). Normas técnicas complementarias para diseño y construcción de estructuras de concreto (NTC-C). Gaceta Oficial del Distrito Federal. México.

[13] GOBIERNO DEL DISTRITO FEDERAL (2004). Normas técnicas complementarias para diseño por sismo (NTC-S). Gaceta Oficial del Distrito Federal. México

[14] GOEL, Rakesh y CHOPRA, Anil (1998). Period formulas for concrete shear wall buildings. Journal of Structural Engineering - ASCE, Vol. 124, No. 4, pp. 426-433.

[15] INSTITUTO MEXICANO DEL CEMENTO Y DEL CONCRETO - IMCYC (2007). Ensaye de núcleos de concreto. Informe Técnico No. 266 realizado para CEMEX Concretos. México, pp. 2-5.

[16] MURIÁ, David; FUENTES, Luís y GONZÁLEZ, Ricardo (2000). Incertidumbre en la estimación de las frecuencias naturales de vibración de edificios de la ciudad de México. En: Revista de Información Tecnológica, Vol. 11, No. 3, pp. 177-184. México.

[17] MURIÁ, David (1997). Edificios instrumentados. En: El macrosismo de Manzanillo del 9 de Octubre de 1995. Editor: A. Tena, Sociedad Mexicana de Ingeniería Sísmica, Universidad de Colima y Gobierno del Estado de Colima, pp. 197-232.

[18] MURIÁ, David y GONZÁLEZ, Ricardo (1995). Propiedades dinámicas de edificios de la ciudad de México. En: Revista de Ingeniería Sísmica, No. 51, pp. 25-45. México.

[19] TENA, Arturo (2007). Análisis de estructuras con métodos matriciales. Editorial Limusa S. A., México.

[20] TRIFUNAC, Mihailo (1972). Comparisons between ambient and forced vibration experiments. En: Journal of Earthquake Engineering and Structural Dynamics. Vol. 1. pp. 133-150. 


\title{
RESISTENCIA AL CORTE EN DISCONTINUIDADES CON DIFERENTES GRADOS DE RUGOSIDAD
}

\section{STRENGTH TO THE CUTTING IN DISCONTINUITIES WITH DIFFERENT DEGREES OF ROUGHNESS}

\author{
Javier Fernando, Camacho Tauta
}

Ing. Civil, MSc., Profesor asistente, Facultad de Ingeniería, Investigador Grupo Geotecnia Universidad Militar Nueva Granada, Bogotá, Colombia, Javier.camacho@unimilitar.edu.co

Oscar Javier, Reyes-Ortiz

Ing. Civil, MSc., Profesor asociado, Facultad de Ingeniería, Investigador Grupo Geotecnia Universidad Militar Nueva Granada, Bogotá, Colombia, oscar.reyes@unimilitar.edu.co

Andrés, Nieto Leal

Ing Civil, MSc, Profesor Auxiliar, Facultad de Ingeniería, Investigador Grupo Geotecnia Universidad Militar Nueva Granada, Bogotá, Colombia, andres.nieto@unimilitar.edu.co

Sebastián, Millán Montejo

Ing. Civil, Joven Investigador e Innovador COLCIENCIAS, Facultad de Ingeniería, Grupo Geotecnia, Universidad Militar Nueva Granada, Bogotá, Colombia, sebastian.millan@unimilitar.edu.co

Fredy, Rincón Morantes

Ing. Civil, Asistente de Investigación, Facultad de Ingeniería, Grupo Geotecnia Universidad Militar Nueva Granada, Bogotá, Colombia, fredy.rincon@unimilitar.edu.co

Fecha de recepción: 27 de abril de 2009

Fecha de aprobación: 11 de junio de 2009

\section{RESUMEN}

En esta investigación se realizaron ensayos triaxiales sobre rocas artificiales elaboradas con un mortero (arena, cemento y agua) de diferente resistencia. Se incluyeron cilindros sin y con una discontinuidad orientada a $60^{\circ}$ con respecto al eje horizontal y tres diferentes grados de rugosidad, (pulida plana, pulida ondulada y ondulada). Se determinaron los parámetros de resistencia de las probetas de mortero y se analizó la influencia de los diferentes grados de rugosidad utilizando el criterio de Barton, obteniendo el coeficiente de rugosidad de la discontinuidad.

Palabras clave: JRC, rugosidad, discontinuidad, triaxial en rocas. 


\section{ABSTRACT}

In this research triaxial testings were done on artificial rocks made with a mortar (cement, sand and water) of different strength. Cylinders were made with and without a discontinuity orientated to $60^{\circ}$ with regard to the horizontal axis and three different degrees of roughness, (polished flat, polished wavy and wavy). The mortar testing strength parameters were obtained and was analyzed the influence of the different roughness degrees by the Barton's criterion, obtaining the roughness coefficient of the discontinuity.

Key words: JRC, roughness, discontinuity, triaxial in rocks.

\section{INTRODUCCIÓN}

Cuando se presentan condiciones topográficas abruptas, las obras subterráneas son una conveniente solución de ingeniería, cruzando macizos rocosos que frecuentemente presentan discontinuidades. Las características de las discontinuidades pueden estudiarse según diferentes parámetros (Ramírez, 1991), que permiten analizar por separado, la incidencia de cada una de estas características sobre las propiedades mecánicas de las discontinuidades y del macizo rocoso. Dos de las características más importantes son la orientación y la rugosidad de la discontinuidad.

La resistencia al corte de una discontinuidad sin presencia de material de relleno está regida por la orientación y rugosidad de la junta (Ramírez, 1991). Por el contrario en discontinuidades con presencia de material de relleno como las arcillas, limos o arenas, el comportamiento de la resistencia al corte se ve afectado por el espesor del material de relleno. Indraratna (1999), muestra que el material de relleno afecta la resistencia al corte en función del espesor de éste, y al mismo tiempo depende del tipo de material de relleno (arcilla, limo o arena).

Para evaluar la resistencia al corte en una discontinuidad con rugosidad, se pueden utilizar dos mecanismos cinemáticos que permiten estudiar el comportamiento de la junta; estos son la dilatancia y la fractura de las irregularidades o rugosidades, el primero se da cuando un bloque se desplaza hacia arriba aumentando el volumen del espécimen, este mecanismo se produce en esfuerzos normales pequeños sobre la superficie de la discontinuidad. El segundo da como resultado una superficie plana, y se genera en esfuerzos normales grandes sobre la superficie de la discontinuidad (Patton, 1966).

En este artículo se presenta el análisis del comportamiento experimental sobre muestras de roca artificial fabricada con mortero, garantizando resistencias baja y media con diferentes tipos de rugosidad (pulida plana, pulida ondulada y ondulada), y con una discontinuidad sin relleno orientada a $60^{\circ}$ con respecto al eje horizontal. 


\section{MARCO CONCEPTUAL}

La estabilidad general de un macizo rocoso está fuertemente influenciada por las características de las discontinuidades presentes en el mismo, por lo tanto el análisis de las discontinuidades es uno de los aspectos más estudiados en mecánica de rocas. Es necesario analizar las relaciones entre el grado de rugosidad de la discontinuidad y los parámetros que permiten estimar su resistencia al corte.

\subsection{RESISTENCIA AL CORTE DE UN NÚCLEO DE ROCA SANA}

Debido a que la envolvente definida por Mohr no tiene un desarrollo matemático, el criterio de Coulomb-Navier define una aproximación de dicha envolvente suponiendo que ésta es una recta dada por la siguiente ecuación (Ramírez, 1991).

$$
\tau_{\theta}=\left(S_{0}+\sigma_{\theta} \tan \phi\right)
$$

Esta recta es llamada recta de Coulomb. La cohesión del material es representada por la variable $S_{0}$, y está definida por el punto de corte de la envolvente de falla con la ordenada en el plano esfuerzo cortante-esfuerzo normal, y el ángulo de fricción interno $\phi$, es el ángulo que se forma entre la envolvente de falla y la horizontal.

\subsection{RUGOSIDAD}

La rugosidad es una medida de la forma de las superficies que conforman la discontinuidad. Una clasificación cualitativa de la rugosidad se basa en la observación de la superficie en dos escalas descriptivas. La escala intermedia (varios metros) que se divide en tres grados: escalonada, ondulada y plana y una escala pequeña (varios centímetros) que divide cada grado de la escala intermedia en: rugosa, lisa y pulida. La Figura 1 presenta una escala descriptiva comúnmente utilizada para clasificar el tipo de rugosidad.

Las escalas cuantitativas están basadas en las medidas de los cambios de inclinación tomadas con discos de diferente diámetro colocados sobre la superficie de la discontinuidad (Hoek, 1985). Helin et al. (2001) proponen el uso de la teoría fractal para caracterizar la rugosidad de la junta. Otra técnica utilizada actualmente es la fotogrametría digital y el procesamiento de imágenes (Unal y Unver, 2004).

\subsection{RESISTENCIA AL CORTE DE LAS DISCONTINUIDADES}

La resistencia al corte es un factor fundamental que se debe considerar en el estudio de las propiedades mecánicas de las discontinuidades. Los elementos más importantes que influyen en el comportamiento de las discontinuidades frente a un esfuerzo cortante son: (Ramírez, 1991). 


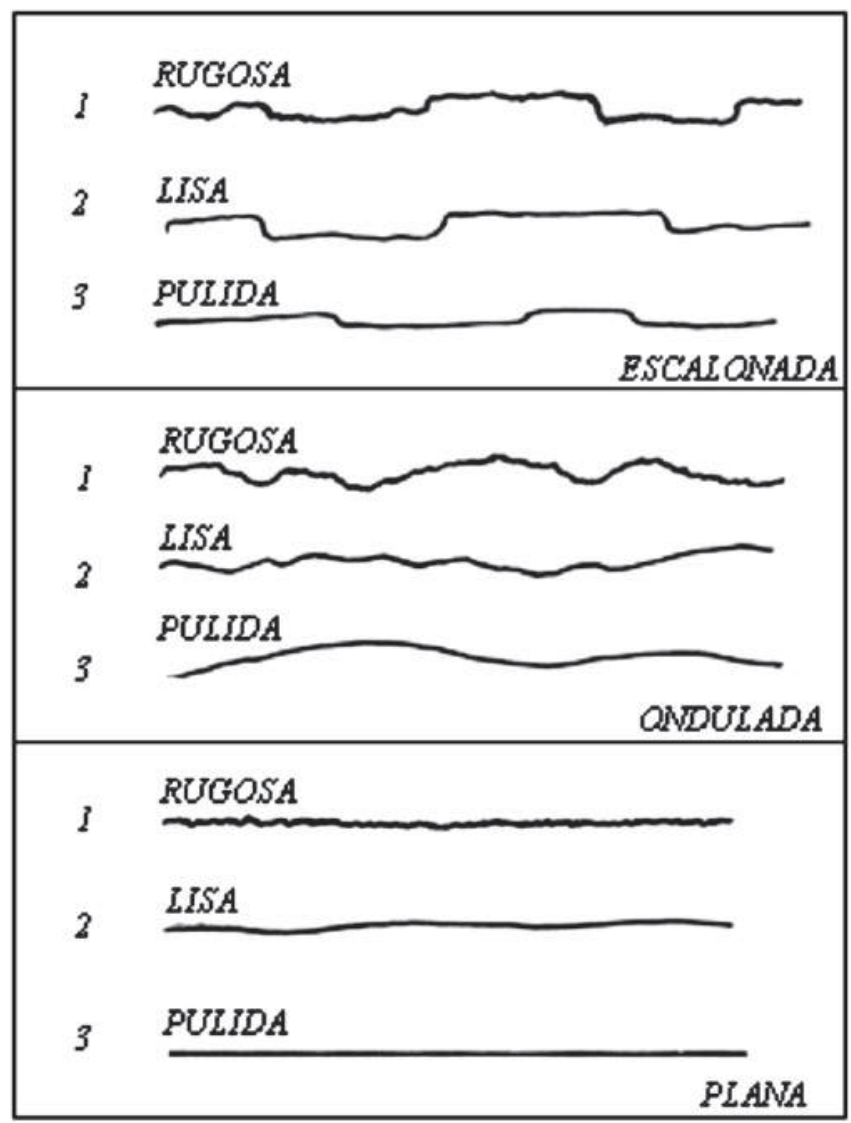

Figura 1. Escala descriptiva de observación para determinar la rugosidad (Hoek, 1981).

- Esfuerzos normales al plano de corte

- Rugosidad de las superficies de contacto

- Grado de alteración y resistencia de los labios de la discontinuidad

- Velocidad del movimiento de corte

- Orientación del desplazamiento

\subsubsection{Discontinuidades planas}

En una discontinuidad plana, es decir sin rugosidad ni ondulación; el ángulo de fricción representa el incremento del esfuerzo de corte debido a la fricción producida entre las superficies de las discontinuidades al aumentar el esfuerzo normal. En una discontinuidad plana, cerrada y sin relleno, la resistencia al corte $(\tau)$ depende del esfuerzo normal $\left(\sigma_{n}\right)$ y del ángulo de fricción básico $\left(\phi_{\mathrm{b}}\right)$, de acuerdo a la Ecuación 2.

$$
\tau=\sigma_{\mathrm{n}} \tan \left(\phi_{\mathrm{b}}\right)
$$




\subsubsection{Discontinuidades dentadas}

Para iniciar el estudio del comportamiento mecánico de una discontinuidad que no sea plana, el modelo teórico que puede utilizarse es el de una discontinuidad cuyas superficies están conformadas por dientes triangulares que encajan perfectamente entre sí.

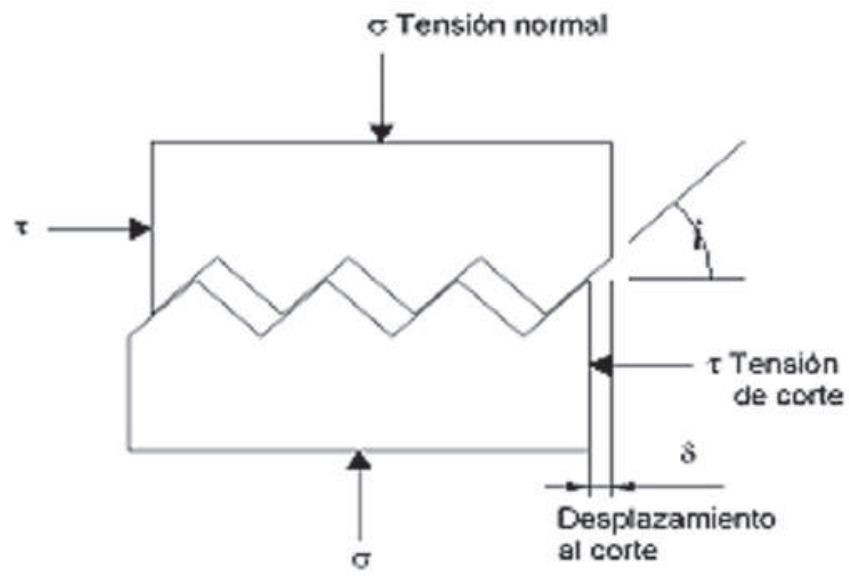

Figura 2. Modelo de discontinuidad conformada por dientes con ángulo uniforme (Ayala, 1987).

En la Figura 2 se representa este modelo de discontinuidad. Patton, citado en Ayala 1987, fue quizás el primero en cuantificar los efectos de las rugosidades en la resistencia al corte de las discontinuidades. En rugosidades que tienen un ángulo de inclinación (i) uniforme, y se encuentra en la dirección de corte, la resistencia al corte se puede calcular de acuerdo con la Ecuación 3:

$$
\tau=\sigma_{\mathrm{n}} \tan \left(\phi_{\mathrm{b}}+\mathrm{i}\right)
$$

\subsubsection{Discontinuidades con perfiles de rugosidad}

Barton y Choubey (1974), desarrollaron un modelo empírico para poder estimar la envolvente de la resistencia al corte para discontinuidades con cualquier tipo de rugosidad. Este criterio es una forma sencilla para poder estimar la resistencia al corte de una discontinuidad mediante ensayos relativamente simples. Se basa en la siguiente expresión:

$$
\tau=\sigma_{\mathrm{n}}\left(\tan \left(\phi_{\mathrm{b}}+\mathrm{JRC}\right) \log _{10}\left(\frac{\mathrm{JRC}}{\sigma_{\mathrm{n}}}\right)\right)
$$

Donde JRC es el coeficiente de rugosidad de la discontinuidad y JCS es la resistencia a compresión simple de los labios en la discontinuidad. El valor de JRC depende del grado de rugosidad de la discontinuidad y varía desde cero para superficies lisas, cre- 
ciendo conforme el perfil de rugosidad aumenta. La Figura 3 presenta una calificación de varios tipos de rugosidad.

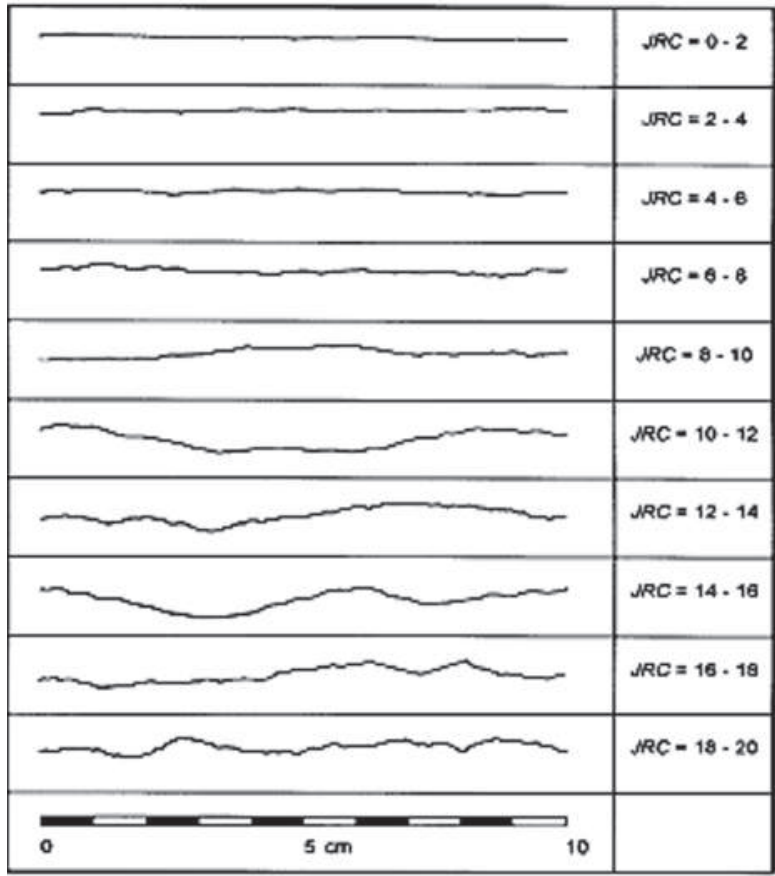

Figura 3. Perfiles de rugosidad y el valor atribuido al coeficiente de rugosidad de la discontinuidad, JRC (Hoek, 2007).

\subsection{ESTADO DE ESFUERZOS EN EL PLANO DE DISCONTINUIDAD}

En un cilindro sometido a un estado triaxial de esfuerzos como el presentado en la Figura 4 , se puede calcular el esfuerzo normal $\left(\sigma_{n}\right)$ y cortante $\left(\tau_{n}\right)$ en el plano de la discontinuidad mediante las Ecuaciones 5 y 6 , respectivamente.

$$
\begin{gathered}
\sigma_{\mathrm{n}}=\frac{1}{2}\left(\sigma_{1}+\sigma_{3}\right)-\frac{1}{2}\left(\sigma_{1}-\sigma_{3}\right) \cos 2 \beta \\
\tau=\frac{1}{2}\left(\sigma_{1}-\sigma_{3}\right) \operatorname{sen} 2 \beta
\end{gathered}
$$

Donde:

$\sigma_{1}:$ Esfuerzo principal mayor

$\sigma_{3}$ : Esfuerzo principal menor

$\beta$ : Angulo entre el plano de discontinuidad y el eje principal mayor

También se representan los esfuerzos principales y los esfuerzos en el plano de la discontinuidad. 


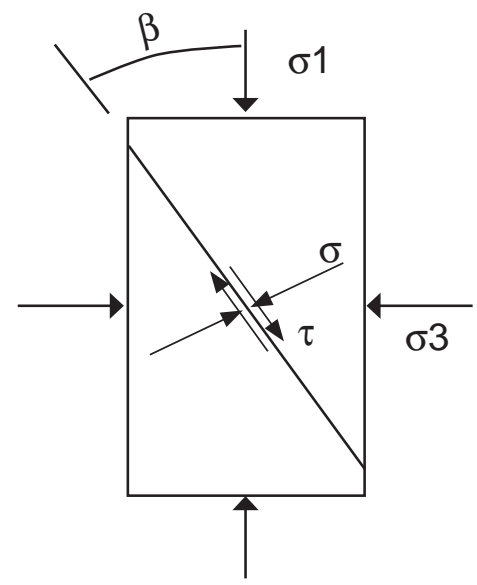

Figura 4. Relación entre los esfuerzos principales y los esfuerzos en el plano de discontinuidad (Hoek, 1985).

\section{METODOLOGÍA}

La investigación se realizó en rocas artificiales de pasta de cemento, con dos resistencias diferentes que simulan la competencia de una roca débil y otra media (tabla 1); con una orientación de la discontinuidad a $60^{\circ}$ respecto al eje horizontal; las dimensiones de las probetas fueron $50.8 \mathrm{~mm}$ de diámetro y $140 \mathrm{~mm}$ de altura.

Tabla 1. Competencia de la roca de acuerdo al ensayo de Compresión uniaxial (Suárez, 1998).

\begin{tabular}{|c|c|}
\hline Compresión Uniaxial (MPa) & Competencia de la Roca \\
\hline 5 a 20 & Muy Débil \\
\hline 20 a 40 & Débil \\
\hline 40 a 80 & Resistencia mediana \\
\hline 80 a 160 & Dura \\
\hline 160 a 320 & Muy Dura \\
\hline
\end{tabular}

La rugosidad utilizada en las probetas se definió con base en la figura 1, donde se ve una escala descriptiva para determinar las rugosidades, y teniendo en cuenta tres perfiles de rugosidad, el primero liso, sin ningún tipo de rugosidad, el segundo con una altura del diente de $1 \mathrm{~mm}$ y $45^{\circ}$ de inclinación que representa una rugosidad media, considerado en la figura 1 como pulida ondulada, y el tercero con una altura del diente de $3 \mathrm{~mm}$ y $45^{\circ}$ de inclinación siendo una rugosidad alta. En este documento se mencionará el grado de rugosidad con base en la altura del diente que genera el perfil rugoso. Se ejecutaron ensayos triaxiales con tres presiones de cámara (2, 6 y $10 \mathrm{MPa})$, para encontrar la envolvente de falla, finalmente se analizó la información obtenida. En la Figura 5 se muestra el diagrama de metodología de la investigación. 


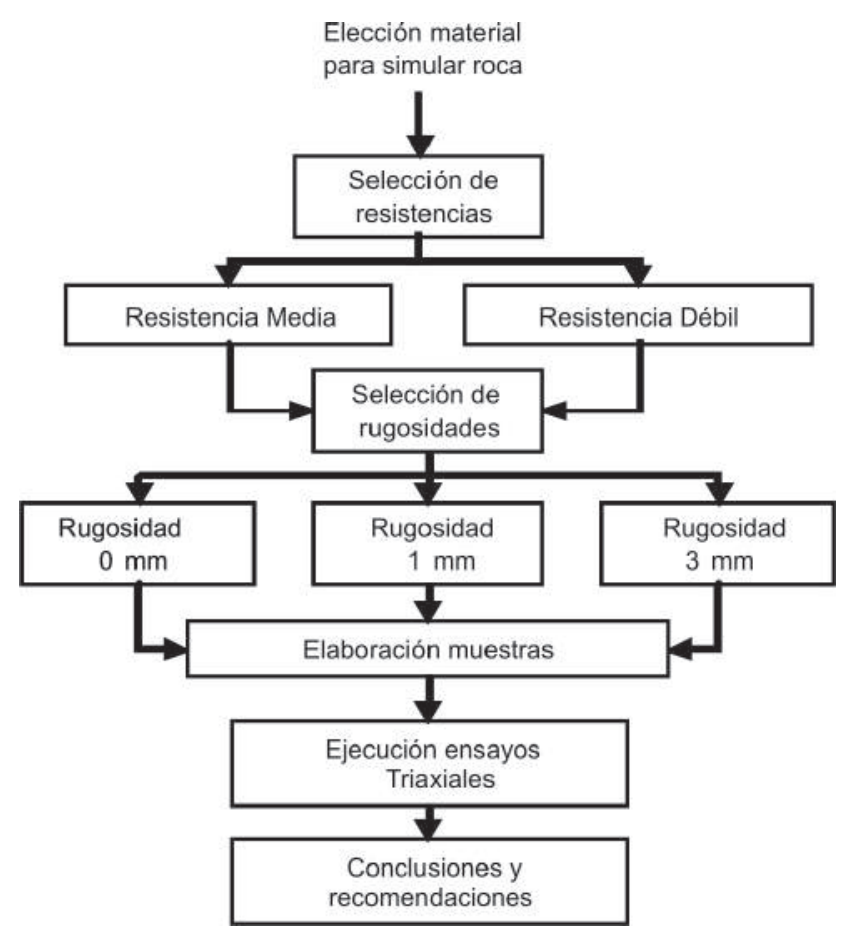

Figura 5. Diagrama metodología de la investigación.

El diseño de mezcla para hallar las resistencias media y baja se logró hallando la relación agua cemento óptima. Se hicieron cubos con pasta de cemento con diferentes relaciones agua-cemento $(\mathrm{a} / \mathrm{c})$ para obtener la resistencia deseada (Figura 6$)$. Se obtuvo una resistencia media con una relación a/c igual a 0.4 , y una resistencia baja o débil con una relación a/c de 0.5 , con siete días de curado.

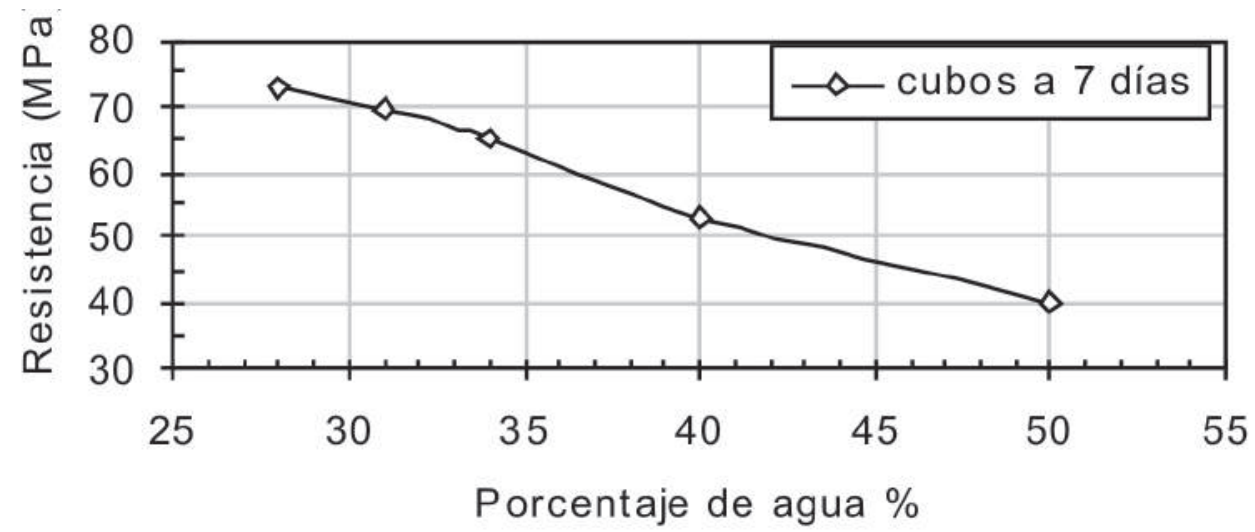

Figura 6. Resistencia a la compresión de cubos a los siete días (López, et al, 2006).

Las probetas a ensayar en el triaxial de rocas se fundieron de tal forma que se pudiera generar una discontinuidad aproximadamente en el centro de éstas, a un ángulo de $60^{\circ}$ 